Old Dominion University

ODU Digital Commons

Spring 2012

\title{
The Impact of Developmental Mathematics Courses and Age, Gender, and Race and Ethnicity on Persistence and Academic Performance in Virginia Community Colleges
}

James Dael Wolfle

Old Dominion University

Follow this and additional works at: https://digitalcommons.odu.edu/teachinglearning_etds

Part of the Adult and Continuing Education Commons, Higher Education Commons, and the Science and Mathematics Education Commons

\section{Recommended Citation}

Wolfle, James D.. "The Impact of Developmental Mathematics Courses and Age, Gender, and Race and Ethnicity on Persistence and Academic Performance in Virginia Community Colleges" (2012). Doctor of Philosophy (PhD), Dissertation, Teaching \& Learning, Old Dominion University, DOI: 10.25777/86zc-c168 https://digitalcommons.odu.edu/teachinglearning_etds/45

This Dissertation is brought to you for free and open access by the Teaching \& Learning at ODU Digital Commons. It has been accepted for inclusion in Teaching \& Learning Theses \& Dissertations by an authorized administrator of ODU Digital Commons. For more information, please contact digitalcommons@odu.edu. 
THE IMPACT OF DEVELOPMENTAL MATHEMATICS COURSES AND AGE, GENDER, AND RACE AND ETHNICITY ON PERSISTENCE AND ACADEMIC PERFORMANCE IN VIRGINIA COMMUNITY COLLEGES

by

$$
\text { James Dael Wolfle }
$$

B.S. May 1991, The Pennsylvania State University

M.S. May 2006, The Pennsylvania State University

A Dissertation Submitted to the Faculty of Old Dominion University in Partial Fulfillment of the

Requirements for the Degree of

DOCTOR OF PHILOSOPHY

CURRICULUM AND INSTRUCTION

OLD DOMINION UNIVERSITY

May 2012

Approved by:

Mitchell Williams (Director)

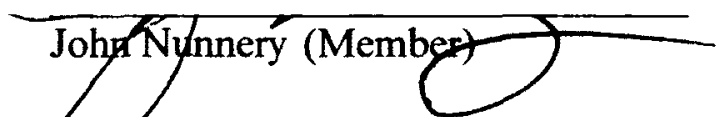

Natalie Harder (Member) 


\begin{abstract}
THE IMPACT OF DEVELOPMENTAL MATHEMATICS COURSES AND AGE, GENDER, AND RACE AND ETHNICITY ON PERSISTENCE AND ACADEMIC PERFORMANCE IN VIRGINIA COMMUNITY COLLEGES
\end{abstract}

James Dael Wolfle

Old Dominion University, 2012

Director: Dr. Mitchell R. Williams

This research study examined the 2006 cohort of First-Time-in-College students from all 23 community colleges in Virginia. The goal was to examine the persistence of these students to the fall 2007 semester and the success of these students in their first collegelevel mathematics course. The main predictor variable was whether the first mathematics course taken was a developmental or college-level course. Other main predictor variables examined were the age, gender, and race and ethnicity of the student. Race and ethnicity was broken into the categories White, Black, and Other. Interaction variables were created to determine if age, race and ethnicity, or gender moderates the effects of developmental status for both persistence and success in the first college level mathematics course, and a model was created using all main and interaction predictor variables to determine to what extent each variable accounts for persistence and success. It was found that neither gender nor race and ethnicity moderates developmental status for either persistence or success, but age moderates both success and persistence. Developmental courses are more effective for traditionally aged students and developmental courses are positively related to the persistence of non-traditionally aged students and negatively related to the persistence of traditionally aged students. The 
predictor variables developmental status, age, race and ethnicity, and gender are all significantly related to both the success and persistence of students. The effect of developmental status on both success and persistence is weak. Non-developmental status, female, non-traditionally aged, and non-Black race and ethnicity are all positively related to the success of students in their first college-level mathematics course. Nondevelopmental status, female, traditionally aged, non-White and non-Black race and ethnicities are all positively related to the fall-to-fall persistence of students. 
(C2012 James D. Wolfle. All rights reserved. 
This dissertation is dedicated to my children. You were the impetus for me to continue my schooling and the motivation to persist to this degree. You brighten my life every day and I hope I am the role model to you to which you deserve. 


\section{ACKNOWLEDGEMENTS}

Earning a doctorate degree is not a solitary journey. There are many people who assisted me in the journey which has culminated with this paper. First and foremost I would like to thank Stephanie Wolfle, my wife, for providing support throughout my entire program. Additionally there were many people who provided care for my children while I was working on this dissertation and degree, most notably Penny Martin and Don Martin who provided time each week throughout my program.

I had a number of colleagues throughout the community college system in Virginia who provided their time to provide feedback and offer suggestions for this study. Two of these people in particular were Donna Jovanovich at the system office of the Virginia Community College System who provided a sounding board at the outset of the project and was valuable in suggesting variables to examine in the study. Also, Kim Hasley who is a fellow instructor at J. Sargeant Reynolds Community College took the time to read and provide feedback and suggestions during my writing. Too many other colleagues to mention individually have provided support and ideas through informal conversations throughout the writing of this dissertation.

I would like to thank the administration at both Tidewater Community College and J. Sargeant Reynolds Community College who provided professional development funding and time to allow me to follow this path and complete this degree and dissertation.

Finally, I would like to thank my dissertation committee members who have helped me with the concepts, ideas, writing, and procedures used in this dissertation over 
the past year. Dr. John Nunnery provided guidance and helped me through the nuts and bolts of logistic regression, creating and understanding variables, and interpreting the output from the models. Dr. Natalie Harder graciously provided her time to help guide and direct this dissertation even through a major promotion and move to a new state.

Finally, Dr. Mitchell Williams has provided me a continual, positive influence throughout the past year of writing this dissertation and was a mentor and guide throughout several courses in my program over the past two years. While extremely busy he was always available to provide feedback, suggestions, and guidance through the writing process and has played a large role in my success in my program.

I have been fortunate to have such a great group of faculty, mentors, colleagues, and friends to help me throughout my journey. I cannot thank you all enough. 


\section{TABLE OF CONTENTS}

Page

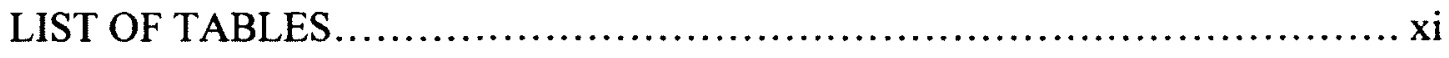

Chapter

I. PROBLEM STATEMENT ................................................... 1

BACKGROUND OF THE PROBLEM................................. 2

PURPOSE STATEMENT .......................................... 8

RESEARCH QUESTIONS ........................................ 8

PROFESSIONAL SIGNIFICANCE ................................ 10

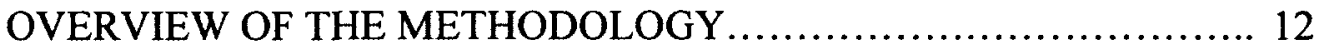

DELIMITATIONS................................................. 14

LIMITATIONS...................................................... 15

DEFINITIONS OF KEY TERMS.................................... 16

SUMMARY ....................................................... 17

II. REVIEW OF THE LITERATURE ...................................... 19

DEVELOPMENTAL EDUCATION................................ 21

DEFINITION OF DEVELOPMENTAL EDUCATION................... 24

SCOPE OF DEVELOPMENTAL EDUCATION...................... 26

DEVELOPMENTAL EDUCATION IN VIRGINIA

COMMUNITY COLLEGES.................................. 30

ACADEMIC SUCCESS IN HIGHER EDUCATION.................... 32

SUCCESS IN DEVELOPMENTAL MATHEMATICS COURSES.........33

SUCCESS OF DEVELOPMENTAL STUDENTS IN COLLEGE-

LEVEL MATHEMATICS COURSES.......................... 35

PERSISTENCE IN THE COMMUNITY COLLEGE.................... 37

PERSISTENCE OF DEVELOPMENTAL STUDENTS.................. 39

TINTO'S MODEL OF STUDENT INTEGRATION........................ 41

RACE AND ETHNICITY OF STUDENTS IN COMMUNITY

COLLEGES AND DEVELOPMENTAL MATHEMATICS........ 43

ACADEMIC SUCCESS OF STUDENTS BASED ON RACE

AND ETHNICITY......................................... 44

PERSISTENCE OF STUDENTS BASED ON RACE AND ETHNICITY. 45

GENDER OF STUDENTS IN COMMUNITY COLLEGES AND

DEVELOPMENTAL MATHEMATICS........................... 46

ACADEMIC SUCCESS OF STUDENTS BASED ON GENDER ........ 46

PERSISTENCE OF STUDENTS BASED ON GENDER .................47

AGE OF STUDENTS IN COMMUNITY COLLEGES AND

DEVELOPMENTAL MATHEMATICS. 
Chapter Page

ACADEMIC SUCCESS OF STUDENTS BASED ON AGE............ 48 PERSISTENCE OF STUDENTS BASED ON AGE................... 50 SUMMARY ............................................................ 51

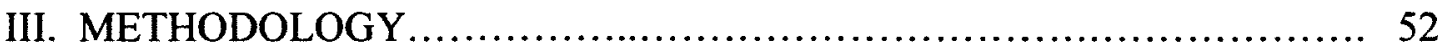

SETTING.......................................................... 54

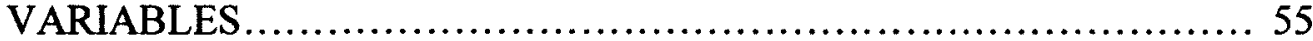

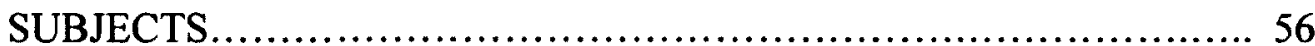

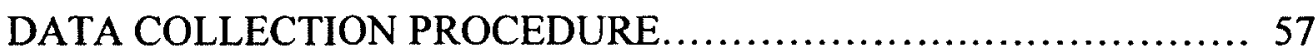

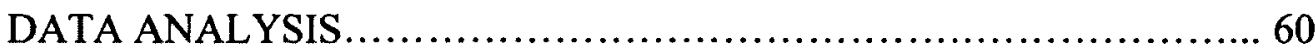

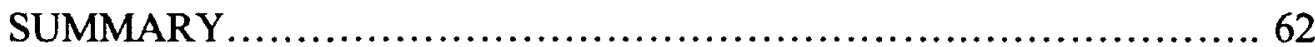

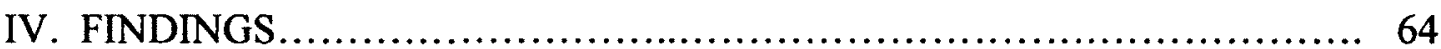

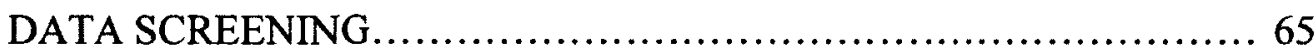

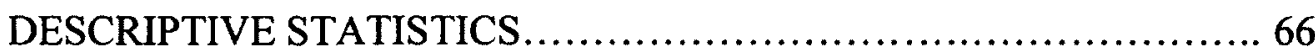

PREDICTIVE MODELS......................................... 68

RESEARCH QUESTION 1: MODERATING VARIABLES ON SUCCESS................................................. 69

RESEARCH QUESTION 2: MODERATING VARIABLES ON PERSISTENCE.......................................... 72

RESEARCH QUESTION 3: EXTENT PREDICTOR VARIABLES ACCOUNT FOR SUCCESS ..................... 75

RESEARCH QUESTION 4: EXTENT PREDICTOR VARIABLES ACCOUNT FOR PERSISTENCE............... 78

SUMMARY .....................................................81

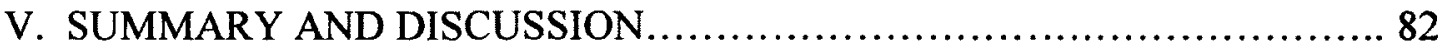

BACKGROUND OF THE PROBLEM.............................. 82

PURPOSE STATEMENT AND RESEARCH QUESTIONS............. 85

SIGNIFICANCE ....................................................87

METHODOLOGY............................................... 87

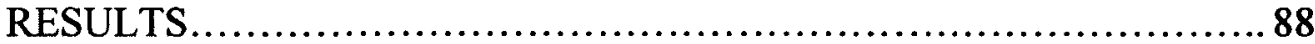

DISCUSSION ..................................................... 89

RESEARCH QUESTION 1: MODERATING VARIABLES ON

SUCCESS ............................................... 90

RESEARCHER INSIGHTS ........................ 92

IMPLICATIONS AND RECOMMENDATIONS FOR

PRACTITIONERS ............................... 93

RESEARCH QUESTION 2: MODERATING VARIABLES ON

PERSISTENCE ............................................. 94

RESEARCHER INSIGHTS ......................... 95 
Chapter

IMPLICATIONS AND RECOMMENDATIONS FOR PRACTITIONERS............................ 96

RESEARCH QUESTION 3: EXTENT PREDICTOR

VARIABLES ACCOUNT FOR SUCCESS................... 97

RESEARCHER INSIGHTS ........................... 101

IMPLICATIONS AND RECOMMENDATIONS FOR PRACTITIONERS.............................. 104

RESEARCH QUESTION 4: EXTENT PREDICTOR

VARIABLES ACCOUNT FOR PERSISTENCE................. 106

RESEARCHER INSIGHTS .......................... 111

IMPLICATIONS AND RECOMMENDATIONS FOR PRACTITIONERS ................................. 113

SUGGESTIONS FOR FURTHER RESEARCH..................... 115

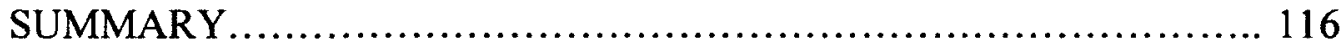

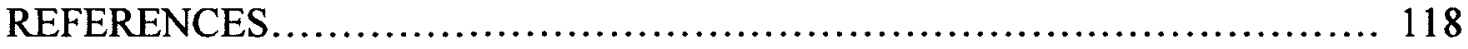

APPENDICES

A. PROBABILITY OF SUCCESS IN THE FIRST COLLEGE-LEVEL MATHEMATICS COURSE.................................. 135

B. PROBABILITY OF PERSISTENCE TO A SECOND YEAR OF COLLEGE. 


\section{LIST OF TABLES}

Table

Table 1 Descriptive Statistics for Sample Demographic Information........67

Table 2 Success in the First College-Level Mathematics Course............ 67

Table $3 \quad$ Persistence to the Fall 2007 Semester............................ 68

Table 4 Crosstabs for Success and Demographic Variables...............69

Table 5 Crosstabs for Persistence and Demographic Variables............. 70

Table $6 \quad$ Logistic Regression Results for Success.......................71

Table 7 Crosstabs for Success by Developmental Status by Age............ 73

Table $8 \quad$ Logistic Regression Results for Persistence..................... 74

Table 9 Crosstabs for Persistence by Developmental Status by Age........ 75 


\section{CHAPTER I}

\section{PROBLEM STATEMENT}

The majority of community college students today are academically unprepared for college (Bailey, 2009; Cohen \& Brawer, 2008). To meet the needs of these underprepared students, colleges offer developmental education to bring the academic level of the student up to the collegiate level (Johnson \& Kuennen, 2004; Virginia Community College System [VCCS], 2009). Offering developmental education to underprepared students is one of the key tasks which have largely fallen to community colleges (Oklahoma State Regents for Higher Education, 2008; Provasnik \& Planty, 2008). Developmental education courses were offered in $98 \%$ of all two-year colleges in 2000 and $42 \%$ of community college first-year students enrolled in at least one developmental course with $35 \%$ of students enrolled in developmental mathematics (Parsad, Lewis, \& Greene, 2003). Individual institutions and organizations at the state and national level have realized the success of developmental students is critical in reaching national, state, and institutional goals on student success (Oklahoma State Regents for Higher Education; Virginia Community College System [VCCS], 2011, United States Department of Education [USDoE], 2006).

In 2008, the Virginia Community College System created the Developmental Education Task Force to begin to focus on the state of developmental education in its 23 member community colleges. This task force affirmed three goals for the system of community colleges in Virginia: 1) to reduce the need for developmental education; 2) to redesign developmental education to allow for completion in less than one year, and 3) to 
increase the number of developmental education students graduating or transferring (VCCS, 2009). Data collected for the Developmental Education Annual Report (VCCS, 2011) show $60 \%$ of the fall 2005 cohort was recommended to take developmental coursework based on their placement scores. The report provided figures for cohorts from 2005 to 2009 and showed the percentage of students placing into developmental courses has steadily increased to $64 \%$ by the 2009 cohort.

The Virginia Community College System collects data to track the progress towards reaching the stated goals created by the Developmental Education Task Force. The purpose of this study will be to examine the third goal created by the Developmental Education Task Force: increasing the success of students. The measures which the Virginia Community College System uses to determine how this goal is being met include persistence of students from fall-to-spring and fall-to-fall semesters, success in developmental courses, success in college level courses, graduation rates, and transfer rates. This study examined two of these measures which were reported in the VCCS Developmental Education Report: persistence of students from the fall semester of 2006 to the fall semester of 2007 and the success students find in their first college level mathematics course.

\section{Background of the Problem}

Developmental education has been a part of the higher educational system in the United States for almost 400 years (Dotzler, 2003). Even with the long history of developmental education, the formal discipline of study entitled developmental education was not founded until the early 1900s (Dotzler) and the first professional organization in 
this field was not founded until 1976 (Boylan \& Bonham, 2007). Early in its history, developmental education was designed to teach students the academic skills which they lacked to be successful in higher education. In the professional literature, the improvement of academic skills is generally called remediation. However, the term developmental education can also refer to the general academic skills which students need to be successful in higher education.

The duplicity of terms, remedial and developmental, is found throughout the professional literature on developmental education, sometimes within the same article. Some researchers examined developmental education as a remediation process (Johnson, \& Kuennen, 2004; Levin, \& Calcagno, 2008) and report their findings in that manner, whereas other researchers (Bharath, 2009; Boylan, Bonham, \& Tafari, 2005; Waycaster, 2001) examined developmental education in a more holistic student-oriented view and report findings in areas other than academic. There are also researchers who use both terms interchangeably (Bailey, 2009; Martinez \& Martinez, 2006). Recent literature (Illich, Hagan, \& McCallister, 2004) and theory (National Association for Developmental Education [NADE], n.d.) have explicitly differentiated between remediation, improving academic content skills, and development, a comprehensive approach to aiding students improve general skills necessary for success in college courses, and indicated developmental education encompasses both concepts. This study will use the term developmental as does the National Association for Developmental Education: including all forms of learning assistance, counseling, advising, and coursework. 
There has been tremendous growth in developmental education over the past 40 years. During this time, the number of students in community colleges has increased $741 \%$ (Provasnik \& Planty, 2008) and the proportion of community college students who require remediation has remained constant at approximately $40 \%$ (Alliance for Excellent Education, 2011; Attewell, Lavin, Domina, \& Levey, 2006; Bettinger \& Long, 2005). The same proportion of students requiring developmental coursework and the large increase in the number of students has significantly increased the number of students requiring developmental courses (Oudenhoven, 2002).

The cost of higher education in this country is great. Community colleges in 2004-05 had expenditures of over $\$ 38$ billon (Provasnik \& Planty, 2008) with over $\$ 1$ billion of that being developmental education (Alliance for Excellent Education, 2011; Bahr, 2008). These costs for developmental education included faculty, support services, and physical space. Bahr argued developmental education puts an undue financial burden on students, devalues post-secondary degrees, and demoralizes faculty who teach these courses. There is concern the outcomes of developmental education do not reflect the investment. Statistics indicate over $75 \%$ of developmental students ultimately did not complete a degree (Bahr; VCCS, 2011). Higher education has received increased scrutiny over the past several years, and developmental education is currently being examined closely throughout the country (VCCS, 2009) which is leading to major changes in both the content and delivery methods of developmental education courses (Gonzalez, 2011; Mireles, 2010). 
McIntosh and Rouse (2009) said "postsecondary education is key for both individual success and economic competitiveness in the global, knowledge driven economy" (p. 1). Colleges and employers are increasingly concerned high school graduates of today do not have the skills necessary to succeed after graduation (Kendall et al., 2007). One possible factor for this lack of preparedness could be the curriculum in high schools (Alliance for Excellent Education, 2011; Wilson, 2008). Wilson particularly concluded students were not as prepared to succeed in mathematics in higher education and surmised the use of calculators on the mathematics portion of the Scholastic Achievement Test was a possible cause of the differences in student readiness for higher education today than it was twenty years ago. Calculator use, and even the practice of using the calculator to solve problems, is indicated in the Virginia Standards of Learning for Algebra II, where over half (11 out of 20) standards explicitly reference using a graphing calculator (Virginia Department of Education [VADoE], 2011). Another leading factor in student need for developmental education is the amount of time which has passed since prior schooling experiences for older students (Tinto, 1993). Teaching older students is particularly common in community colleges as more than $50 \%$ of community college students are older than 23 (Provasnik \& Planty, 2008).

Increased scrutiny of student outcomes of developmental education has become more prevalent over the past several years (Florida Department of Education [FLDoE], $2011 \mathrm{a}$; VCCS, 2009). In other words, the public, government agencies, funding agencies, and higher education institutes are asking if developmental education raises the skills of students to the level which is required to be successful in college-level coursework. One 
way to measure this is to compare the success of students who enroll in developmental coursework with the success of students who do not require such coursework. The results of past comparisons of these groups of students are conflicting. Some research (Bahr, 2008; Calcagno, 2007, Waycaster, 2001) has found similar levels of success between students taking and not taking developmental courses and other research (Biegel, 2009; Germanna Community College, 2001; Gonzales, 2007; Parmer \& Cutler, 2007) have found students who enrolled in developmental courses had lower levels of success in college-level courses than students who did not enroll in developmental courses.

One other commonly researched topic in education is the persistence of students in their programs. Particularly, how does the requirement of taking developmental coursework affect the persistence of students? There is evidence successfully completing a developmental mathematics course improves persistence (Fike \& Fike, 2008), or at least it does not significantly change the persistence of students (Calcagno, 2007; Moore, 2006). Examining the persistence of students to a second year of higher education, typically called fall-to-fall persistence, is an appropriate measure as more than half of the students who drop out of college do so during their first year (Tinto, 1993) and close to half of all community college students drop out before obtaining their degree (Calcagno, Bailey, Jenkins, Kienzl, \& Leinbach, 2008; Fike \& Fike). Thus, improving the persistence of students is a goal for colleges for both financial and planning reasons (Tinto).

Tinto's (1993) model of persistence in higher education states persistence increases when students are socially integrated into the school. This integration is 
difficult to accomplish in non-residential schools and the applicability of Tinto's integration theory to community colleges has been questioned (Bailey, Calcagno, Jenkins, Kienzl, \& Leinbach, 2005; Tinto). Recent research has shown persistence in community colleges can be increased by social integration similarly to traditional fouryear colleges (DuBray, 2005; Karp, Hughes and O'Kara, 2010). Tinto said "nowhere is the importance of student involvement more evident than in and around the classrooms of the college" (p. 132). In many community colleges, and particularly in Virginia community colleges, developmental courses meet for longer periods of time than college level courses and often have fewer students in each section as compared to college-level courses. Successful completion of a developmental course has been found to be positively correlated with student retention (Fike \& Fike, 2008) and reasons which have been suggested for this include smaller class sizes and the special attention students receive (Waycaster, 2001), increased instructional time with faculty (Kisker \& Outcalt, 2005), and an atmosphere where students can feel connected to the school (Lesik, 2007).

The Developmental Education Task Force (VCCS, 2009) described a turning point in developmental education in Virginia community colleges. It reported developmental education in Virginia was no longer about access but about improving the success and experiences of developmental students. To ensure this improvement occurred, the task force recommended, in part, redesigning developmental courses, working with high schools to improve student readiness, improving student support services, and collecting data on first-time-in-college students to help ensure accountability at the college and state level (VCCS, 2009). The Developmental 
Education Annual Report (VCCS, 2011) was the first compilation of data recommended by the Developmental Education Task Force. The Developmental Education Annual Report described the 2006 cohort of first-time-in-college students and provided descriptive statistics about this cohort on measures designed to address the recommendations. Understanding which developmental students are struggling to meet standards will help the Virginia Community College System better direct funds and other resources to aid those students. This study extended the knowledge presented on the 2006 cohort from the Annual Report and statistically examined the differences between developmental and non-developmental students and their success in the first college level mathematics course taken and their persistence into a second year of college.

Purpose Statement

The purpose of this quantitative study was to examine the effect of age, gender, and race and ethnicity together with developmental mathematics status on student's persistence to a second year and academic performance in the student's first college level mathematics course in Virginia community colleges. This study utilized the data reported by the Virginia Community College System in: "Developmental Education Annual Report: Tracking the Fall 2006 Cohort and Five-Year Historical Trends" (VCCS, 2011).

\section{Research Questions}

This study was guided by the following research questions: 
1. Are there moderating variables on developmental mathematics status in determining the success of Virginia community college students in their first college-level mathematics course?

a. Does student race and ethnicity moderate the effects of developmental mathematical status on the success of Virginia community college students in their first college-level course?

b. Does student gender moderate the effects of developmental mathematical status on the success of Virginia community college students in their first college-level course?

c. Does student age moderate the effects of developmental mathematical status on the success of Virginia community college students in their first college-level course?

2. Are there moderating variables on developmental mathematics status in determining the fall-to-fall persistence of Virginia community college students?

a. Does student race and ethnicity moderate the effects of developmental mathematical status on the fall-to-fall persistence of Virginia community college students?

b. Does student gender moderate the effects of developmental mathematical status on the fall-to-fall persistence of Virginia community college students? 
c. Does student age moderate the effects of developmental mathematical status on the fall-to-fall persistence of Virginia community college students?

3. To what extent do developmental status, gender, age, race and ethnicity, and interactions between developmental status and age, developmental status and gender, and developmental status and race and ethnicity account for success of Virginia community college student in their first college-level mathematics course?

4. To what extent do developmental status, gender, age, race and ethnicity, and the interaction between developmental status and age, developmental status and gender, and developmental status and race and ethnicity account for the fall-to-fall persistence of Virginia community college students?

\section{Professional Significance}

Developmental education affects a large number of community college students and is a large part of department budgets for community colleges, particularly in mathematics departments. Developmental courses can lead to the non-completion of degrees or programs offered by the college. Understanding how students who complete developmental courses perform in credit-level courses is an important resource in evaluating the costs and rewards of developmental education programs. "Despite the fact that remedial education is a large component of the two-year college curriculum, the body of research on its effectiveness is rather small and produces mixed findings' (McIntosh \& Rouse, 2009, p. 15). 
Whereas studies on persistence in four-year and residential colleges are numerous, the quantity of such research which focuses on community colleges is limited. Community colleges are mostly commuter schools and students often do not spend much time on campus outside of their courses. The commuter nature of community colleges has created a common perception among researchers, including Tinto, that it is difficult to link persistence in the community college with the level of socialization to the college by the student. In recent literature (Karp et al., 2010) the link between Tinto's socialization theory (Tinto, 1993) as it applies to community colleges has been examined and socialization has been found to occur in the community college. This socialization is often attributed to relationships formed in the classroom. Developmental courses, with increased class-time over college-level courses, could aid in socializing students with the school (Kisker \& Outcalt, 2005; Lesik, 2007). If a link is found between students who enroll in developmental courses and increased persistence it would allow past research on persistence in four year schools to be applied to community college students. This application of research on Tinto's socialization theory could help build knowledge on the persistence of community college students which could aid in the creation of more effective retention programs for community college students.

Studies of large, state-wide, groups of community college students in California (Bahr, 2007, 2008), Florida (Calcagno, 2007), Ohio (Bettinger \& Long, 2005), Tennessee (Threadgill, 2005), and Virginia (Roksa, Jenkins, Zeidenberg, \& Cho, 2009) along with a study of a large multi-state population (Attewell et al., 2006) generally found that there was no difference in the success of developmental students compared to non- 
developmental students, and the persistence of developmental students was either the same or greater than that of their non-developmental counterparts. This study adds to the knowledge base on developmental students in large, state-wide populations.

Additionally, this study has significance in Virginia as it adds to the baseline statistical data for the current developmental mathematics curriculum. The VCCS has changed the format of their mathematics developmental courses throughout the state based on their report "The Turning Point" (VCCS, 2009). This report called for a system-wide annual report to track the progress towards state-wide goals. The first of these annual reports was presented in the Developmental Education Annual Report (VCCS, 2011) which presented descriptive statistics for multiple measures. This study examined the data from the Developmental Education Annual Report statistically and provided data on the success and persistence of students based not only on developmental status as the Developmental Education Annual Report does, but also on common demographic information: age, gender, and race and ethnicity. Addressing common demographic groups provides more detail on the success measures of the current developmental mathematics courses and provides a better comparison for the results of the redesigned system of developmental mathematics courses, which was implemented in VCCS schools during the Spring 2012 semester.

\section{Overview of the Methodology}

Ex post facto data were gathered for all students who enrolled in one of the 23 Virginia community colleges for the first time in the fall 2006 semester and was collected from a five year period. First-Time-in-College students for the fall 2006 semester also 
includes students who first enrolled during the summer 2006 semester, and those students were included in the sample for this study. The data were collected from the Virginia Community College System which compiles data from all 23 community colleges in Virginia. The collected data included student demographic information on age, gender, and race and ethnicity; all mathematics courses taken between fall 2006 and spring 2011; the grade for each mathematics courses; and the enrollment status of the student for each semester from fall 2006 through spring 2008.

Students who were not of either traditional or non-traditional ages, i.e. those students less than age 17, were eliminated from the sample. Students who did not enroll in a mathematics course their first semester, fall 2006 , were eliminated from the sample when evaluating persistence to allow fall-to-fall persistence based on the first mathematics course taken to be determined. Dichotomous variables were created with a value of 1 given to determine persistence (being enrolled in the fall 2007 semester), success in the first college-level mathematics course attempted (earning an A, B, or C), age (being 23 or older), gender (being female), black (being of Black race and ethnicity), and other ethnicity (being of non-White and non-Black race and ethnicity). The interaction variables developmental*age, developmental*gender, developmental*black, and developmental*other were created to determine moderation effects. These dichotomous variables were then used throughout the remainder of the study.

Descriptive statistics were reported for each variable. Cross tabulations were reported for age, gender, and race and ethnicity together with developmental status for students who persisted and did not persist, and for successful students and non-successful 
students. Logistic regressions were utilized to answer the research questions. Two separate models were created, one model used the criterion variable success and the other used the criterion variable persistence. Each regression contained the predictor variables developmental status, age, gender, black, other ethnicity, and interaction variables developmental*age, developmental* ${ }^{*}$ gender, developmental*black, and developmental ${ }^{*}$ other. The coefficients of the interaction variables were tested for significance. The results from each model were examined to determine the extent to which each variable accounted for both persistence and academic success. SPSS version 19 was used to perform all calculations.

\section{Delimitations}

This study utilized data previously gathered by the Virginia Community College System on the 2006 cohort of First-Time-in-College students. This report provided a basis for recommendations for the VCCS to redesign their mathematics developmental education program and is the latest information compiled by the state. The use of this particular data set provided a detailed look at this particular group of students but may not reflect characteristics of students in different cohorts or from different states.

This study utilized ex post facto data which limits the type of data which is possible to collect. This study assumed the data were reported correctly by the student, reported to the VCCS system correctly, and all data were delivered accurately.

There are multiple definitions found in the professional literature of the terms and variables used in this study. This study used a particular definition of each variable, particularly persistence, success, age, and categories for race and ethnicity. The 
definitions for these variables used in this study are presented in a future section. Findings could be different if different definitions of these terms had been used.

Developmental education encompasses all forms of learning assistance including not only the delivery of material in the classroom but also ancillary resources such as tutoring centers, counseling services, supplemental instruction, and mentoring. Whereas the description and learning objectives of each course is the same in all Virginia community colleges, this study did not measure the availability or use of additional institutional resources which are included in concept of developmental education. There may be differences in success or persistence of students across different colleges based on the availability of these additional resources which are not measured in this study.

Finally, there are many topics of interest to the community college community with regard to developmental education and there are many characteristics of students which affect both success and persistence. Many of these characteristics are measureable with the use of ex post facto data and there are many characteristics which cannot be measured. This study focused solely on the variables persistence, success, developmental status, age, gender, and race and ethnicity. Effects found while examining only these variables may not be the same when taken together with other variables.

\section{Limitations}

This study tested for statistical differences between students who completed a developmental course in mathematics and students who were not required to enroll in a developmental mathematics course using the variables age, gender, and ethnicity. Causality was not able to be determined. There are many possible factors which would 
related to academic performance and persistence which due to both the nature of an ex post facto study and researcher choice were not addressed.

\section{Definitions of Key Terms}

- Academic performance (success) - Academic performance was defined as either success or failure depending on the final grade in a college level mathematics course. Success was defined as a grade which will transfer to a four-year institution: an A, B, or C. Failure was defined as a D, F, or W. This is the coding which was used in the VCCS Developmental Education Annual Report (VCCS, 2011).

- Age - Age was defined as either traditionally college aged, or non-traditionally college aged. Non-traditionally aged students were defined as those of ages 23 and older as defined in the VCCS Developmental Education Annual Report (VCCS, 2011). Traditionally age students were defined as aged 17-22. Calcagno, Crosta, Bailey, and Jenkins (2007a) used 17-24, this study used a high age range of 22 to match the definition used by the VCCS).

- College-level course - A college-level course is a course in "the first two years of a baccalaureate program in arts and sciences and pre-professional programs meeting standards acceptable for transfer to baccalaureate degree programs" (VCCS, n.d., section 5.0.1).

- Developmental education - Literature on this subject uses both 'remedial' and 'developmental' to describe courses intended to raise academic skills. This study uses only the term developmental. This term was defined as: "Developmental 
education programs and services commonly address(ing) academic preparedness, diagnostic assessment and placement, development of general and disciplinespecific learning strategies, and affective barriers to learning. Developmental education includes, but is not limited to: all forms of learning assistance, such as tutoring, mentoring, and supplemental instruction; personal, academic, and career counseling; academic advisement; and coursework" (NADE, n.d.)

- $\quad$ Race and Ethnicity - Race and Ethnicity was defined as Black, White, or other ethnicity (non-White and non-Black).

- Gender - Gender was defined as either male or female.

- Persistence - This term was defined as a student who continued to be enrolled in the institution in the fall 2007 semester. This is also commonly termed first-year fall to second-year fall retention, or more succinctly fall-to-fall persistence (Fike \& Fike, 2008).

\section{Summary}

This chapter described the motivation and importance of examining the success and persistence of developmental students and the main issues which affect the problem. The purpose of the study and the research questions which guided the study were presented. Finally, a brief explanation of the methodology used to answer the research questions was presented followed by definitions of the key terms used in the study. The remainder of this paper will add further detail on past research and the methodology used in the current study. Chapter II will present the results of a review of the current literature in the field of developmental education and the status of developmental 
education in Virginia. It will then examine the literature on success and persistence of developmental students, and will then examine the issues and literature on the success and persistence of students of different ages, race and ethnicities, and genders. Chapter III will provide a complete description of the methodology used in the current study. This description will include the variables used, subjects, data collection, and the process for analyzing the data. Chapter IV will present the findings from the study, and will provide tables presenting descriptive statistics on the success and persistence of the sample along with the demographic variables. It will present the key statistics from the models created to determine the extent predictor variables affect the success and persistence of Virginia community college students. Finally, chapter $\mathrm{V}$ will provide a summary of the current study and will present a discussion of the findings as they relate to prior research. It will also describe implications of the findings to practitioners in the community college and will suggest areas for future research. 


\section{CHAPTER II}

\section{REVIEW OF THE LITERATURE}

The Virginia Community College System (VCCS) has been focusing on developmental education over the past four years with the goal of becoming the "premier purveyor of developmental education, in more streamlined and efficient ways, resulting in greater rates of student success" (VCCS, 2009, p. 4-5). This examination began with the Developmental Education Task Force, which found the VCCS had a duty to its students to increase enrollment, increase persistence of students, and attain academic success as measured through credential attainment (VCCS, 2009). Additionally, this Task Force found the success of developmental education students was critical to meet the VCCS goals and the success of these developmental students is now a cornerstone in the system's strategic plans.

The Developmental Education Annual Report (VCCS, 2011) compiled data examining the 2006 cohort of first-time-in-college students at all 23 Virginia community colleges. Descriptive demographic data and data to answer four measureable outcomes were compiled by the VCCS to measure the goals identified by the Developmental Education Task Force. Particularly, two of these measures were designed by the VCCS to describe the success of developmental students in college. The two measures were: fall to fall persistence of students and a comparison by developmental education status of success rates for students who enrolled in college level mathematics courses by the end of year 2. Descriptive statistics reported by the VCCS (VCCS, 2011) indicated $52 \%$ of students who did not enroll in developmental courses persisted to the fall of their second 
year and $59 \%$ of developmental students persisted to the fall of their second year. The report also showed $73 \%$ of students who did not take developmental mathematics passed their first college level mathematics course and $67 \%$ of developmental students passed their first college level mathematics course.

This study aims to further examine this cohort of students and determine factors which may lead to predicting the persistence and success of Virginia community college students. The Developmental Education Annual Report presented descriptive statistics. Whereas that report presented differences between the persistence and success rates of developmental and non-developmental students it did not conduct a statistical analysis of those differences to determine if they were statistically significant. This study will extend the results presented in the VCCS report and will examine the success and persistence of students using additional demographic criteria to determine if there are any significant differences between developmental and non-developmental students, or if age, gender, or race and ethnicity moderates differences between developmental and nondevelopmental students.

This chapter will examine the professional literature on developmental education and how age, gender, and race and ethnicity of a student affects their success and persistence. This chapter will first examine the history of developmental education, definitions of developmental education and the prevalence of developmental education in the United States. Then developmental education in the Virginia Community College System will be described. Literature detailing studies on the two dependent variables, academic success and persistence, will then be reviewed. Finally, the independent 
variables, race and ethnicity, age, and gender and how research has reported their relationships in predicting success and persistence of higher education students, particularly community college students, will be explored.

\section{Developmental Education}

Developmental education first appeared in the United States in 1636 when Harvard was founded, in part, to teach remedial reading to adults (Dotzler, 2003). The first post-secondary institution to create a department which prepared students for college-level work was the University of Wisconsin in 1849 (Dotzler). The Morrill Act of 1862 provided land to each state to create agriculture and mechanical arts programs. These institutions combined with the inclusion of women, freed slaves, and returning service members created a great period of growth in higher education during the late 1800 s and early 1900s (Dotzler). Most colleges were operating their own remedial programs (Cohen \& Brawer, 2008) to meet the needs of these new students.

Even though offering remediation to incoming students of higher education had been a part of higher education for centuries, "it was not until the publication of the Truman Commission Report in 1947 that a national mandate for developmental education was initiated and placed within the mission of the community college" (Crews \& Aragon, 2004, p. 1). It took another decade for widespread study and experimentation to be conducted in developmental education (Dotzler, 2003). As developmental education became increasingly important in higher education, the National Center of Developmental Education was founded in 1976 (Boylan \& Bonham, 2007). The growth of developmental education in need, availability, and importance to society has led to a 
more detailed examination of the results, costs, and benefits of developmental education by researchers. Developmental education is becoming a more critical topic as students are less-prepared for higher education (Cohen \& Brawer, 2008) and higher education is more important for success in today's society (Alliance for Excellent Education, 2011; Cohen \& Brawer; USDoE, 2006). Particularly, the United States Department of Education [USDoE] (2000) stated: "college readiness is one of seven national education priorities" and the United States Government and private groups are providing additional funding to higher education to create more graduates (Attewell et al., 2011).

Developmental education is critical in meeting the goal of creating more graduates of higher education as students are entering higher education unprepared to meet the demands of college-level academic work (Bailey, 2009; Cohen \& Brawer, 2008). The unpreparedness of students for college-level work is particularly acute in community colleges and other two-year institutions (Cohen \& Brawer; McIntosh \& Rouse, 2009) as these institutions generally have an open admissions policy, admitting any student who desires to enroll (Ayers, 2002; Florida Department of Education [FLDoE], 2011b; Provasnik \& Planty, 2008; Shelton \& Brown, 2008). Particularly, the Commissioner of the Texas Higher Education Coordinating Board stated: "When an institution admits a student, it accepts the responsibility to do everything it can to help that student succeed... this responsibility demands that colleges and universities embrace remedial or developmental education as part of their mission" (Martinez \& Martinez, 2006, p. ii) and the Developmental Education Task Force of the Virginia Community College System reported: "community colleges have a unique mission (to) help under- 
prepared students to be successful in college work" (p. 4). Moss and Yeaton (2006) stated: "there is good reason to believe that developmental education offers a viable approach to rectifying problems resulting from more open access to higher education" ( $p$. 217).

The cost for developmental education is high and has been reported to be between one and two billion dollars annually (Alliance for Excellent Education, 2011; Bailey, Jeong, \& Cho, 2010; Bahr, 2008; Martorell \& McFarlin, 2007; Saxon \& Boylan, 2001). Critics of developmental education state these funds are wasted for taxpayers are paying them twice: once for secondary schools and once in higher education (Alliance for Excellent Education). Although the monetary cost of developmental education does appear large, it accounts for less than $10 \%$ of all education expenditures. In most cases the percentage of developmental education costs compared to total college cost is one or two percent (Oklahoma State Regents for Higher Education, 2008; Saxon \& Boylan). Irrespective of the financial costs of providing developmental education "the cost of not offering the courses appear to be expensive" (Bettinger \& Long, 2009, p. 761). Bettinger and Long specified some of the costs of not providing developmental work in higher education as higher incidences of unemployment, government dependency, and incarceration. Spann (2000) put a dollar figure on students who complete developmental education courses when he said if only one third of students in developmental education graduated, they would generate more than $\$ 85$ billion in federal, state, and local taxes. Spann further said graduation rates for developmental students would have to be less than $1 \%$ for there to be a net financial loss to taxpayers. Saxon and Boylan supported this 
view when they reported the costs of delivering remedial education were fully covered or exceeded by the revenues.

\section{Definition of Developmental Education}

There are many different definitions used to describe developmental education in the professional literature. One of the major differences between these definitions is the use of the terms 'remedial' and 'developmental'. Remediation is "a class or activity intended to meet the needs of students who initially do not have the skills, experience or orientation necessary to perform at a level that the institutions or instructors recognize as 'regular' for those students" (Grubb and Associates, 1999, p. 174). The term remediation implies a student has a deficit which needs fixing. Similar to medical practice, the view of remediation has generally consisted of a diagnosis (diagnostic test), a treatment (the remedial course), and an evaluation to see if remediation worked. If it didn't, the treatment, or course, is repeated (Casazza, 1999).

As researchers have examined developmental education in more detail in the past several decades there has been a shift from a narrow, remediation view of developmental education focusing only on improving skills in a particular subject (Boylan \& Bonham, 2007; Illich et al., 2004; Johnson \& Kuennen, 2004). Current practice in the developmental education literature considers "remedial coursework is only one part of a developmental approach" (Oudenhoven, 2002, p. 35). Bettinger and Long (2005) provided a definition for developmental education which encompasses a more holistic improvement of student skills by saying: "the purpose of remedial education is to provide underprepared students with the skills necessary to succeed in college and gain 
employment in the labor market" (p. 19). The separate goals of improving content skills and the general skills necessary to be successful in higher education is an important distinction to make. Researchers commonly attribute both remediation of academic skills and improving the general skills of students as different parts of developmental education when they make statements such as: "developmental education refers to a broad range of courses and services" (Boylan \& Bonham, 2007, p. 2) and "includes, but is not limited to, tutoring, personal and career counseling, academic advisement and coursework" (Casazza, 1999, Who are we section, para. 2). Those currently in the field of developmental education draw distinctions between the terms remedial and developmental and strongly prefer the latter (Kozeracki, 2002).

The roots of developmental education as practiced today can be traced back to The Student Personnel Point of View, published in 1937 (Higbee, Arendale, \& Lundell, 2005). Illich et al. (2004) described the definition most used today for developmental education as encompassing a more complete range of services to the student, including counseling, tutoring, study skills, and other support services. Illich et al. argued if developmental education were defined as only the need to address improving academic skill areas in a particular subject this would imply students would be successful in other academic areas. Their study found that implication did not hold true for many developmental students.

According to the VCCS, "the purpose of developmental education is to prepare students for college-level work" (VCCS, 2009, p. 12). How the VCCS plans to prepare students is not defined. A more complete definition for developmental education is 
provided by the National Association of Developmental Education (NADE). The NADE defines developmental education as:

"a field of practice and research within higher education with a theoretical foundation in developmental psychology and learning theory. It promotes the cognitive and affective growth of all postsecondary learners, at all levels of the learning continuum. Developmental education is sensitive and responsive to individual differences and special needs among learners. Developmental education programs and services commonly address academic preparedness, diagnostic assessment and placement, development of general and discipline-specific learning strategies, and affective barriers to learning. Developmental education includes, but is not limited to:

- all forms of learning assistance, such as tutoring, mentoring, and supplemental instruction,

- personal, academic, and career counseling,

- academic advisement, and

- coursework" (NADE, n.d.).

\section{Scope of Developmental Education}

The need for developmental education in higher education today is great, particularly in community colleges (Martorell \& McFarlin, 2007). The most common developmental subject students require is mathematics (Alcorta, 2009; Mireles, 2010; Roksa et al., 2009; Sullivan, 2010). Approximately $40 \%$ to $50 \%$ of all college students 
enroll in at least one developmental level course (Alliance for Excellent Education, 2011; Attewell et al., 2006; Bettinger \& Long, 2005; Cohen \& Brawer, 2008; Kozeracki, 2002; Oudenhoven, 2002; VCCS 2009). In community colleges, the percentage of students requiring developmental education approaches $60 \%$ (Bailey, 2009) and for some demographic groups and areas of the country this percentage has been reported as high as 80\% (Alcorta, 2009; Alvarez, 2008; Bharath, 2009; Oklahoma State Regents for Higher Education, 2008). The percentage of students enrolled in developmental education has remained consistent over the past thirty years (Provasnik \& Planty, 2008). However, as the number of students enrolling in community colleges has increased more than $700 \%$ over the past 40 years (Provasnik \& Planty) and has increased between 14\% and 27\% over the past six years (FLDoE, 2011b; VCCS 2011) the number of students requiring developmental courses has significantly increased (Oudenhoven). The increased number of students in developmental education demonstrates the need for developmental education which was found by Linfante (2002) who reported "those students in remediation programs that did succeed would not have without remediation" (p. 86).

One difficulty in discussing the scope of developmental education is the lack of consensus about the necessary skills students need in college (Bailey, 2009; Cohen \& Brawer, 2008). Kozeracki and Brooks (2006) stated "what constitutes developmental education varies from institution to institution" (p. 63). Community colleges in different states not only use a variety of diagnostic tests to determine the need for incoming students to enroll in developmental courses, but community colleges from states which use the same test often use the test results differently to determine developmental need 
(Bailey; Cohen \& Brawer; Shelton \& Brown, 2008). These tests also only assess content knowledge and not other developmental needs of students (Bailey; Shelton \& Brown). Therefore, strong students with weak content skills would be referred to developmental education in situations where they may be successful going directly to college-level courses (Cohen $\&$ Brawer) or students may pass the test based on their subject knowledge but may lack skills such as note taking or study habits which are necessary for college success (Bailey). This has led some researchers to question the ability for diagnostic tests to provide a distinction between developmental and college-level students (Bailey; Shelton \& Brown).

Addressing the needs of developmental students in development courses can be problematic as students require developmental coursework for diverse reasons (Cohen \& Brawer, 2008; Oudenhoven, 2002). Developmental students vary from those deficient in many subjects to those deficient in only one (Levin \& Calcagno, 2008; Provasnik \& Planty, 2008). Ages of developmental students range from those just graduating from high school and requiring developmental work to address deficiencies in their secondary education to older students who need developmental course work due to the need to refresh skills which are weak from disuse (Kozeracki, 2002; Tinto, 1993). Developmental students may have poor study habits or have learning problems. Levin and Calcagno also reported many community college students come from immigrant populations which may have the skills for college-level work but lack English skills.

The most commonly reported characteristic of students who require developmental coursework is poor high school preparation (Attewell et al., 2006; Bailey 
et al., 2010; Bettinger \& Long, 2005; USDoE, 2006; Wilson, 2008) which has been the blame for underprepared students for over 100 years (Casazza, 1999). Particularly, the USDoE reported only 17 percent of graduating high school seniors in 2000 were considered proficient in mathematics. The number of students leaving high school unprepared for college-level work is growing, as the proportion of students taking developmental coursework within one year of graduating high school is increasing (Kozeracki \& Brooks, 2006). Underprepared high school graduates can be characterized by poor high school grades, poor scores on national tests such as the ACT or SAT, and a low number of mathematics courses taken in high school (Bettinger \& Long, Wilson). The number of high school students who are not prepared for college-level mathematics has also been attributed to a poor correlation of high school mathematics standards to college mathematics standards and specific policies of state educational boards (Martino \& Wilson, 2009; U. S. Department of Education, Wilson).

Jenkins and Boswell (2002) surveyed community college boards in 47 states and found no state uses high school exit exams to determine placement in developmental courses. They suggested that not using high school exit exams to determine college placement indicates standards for high school completion and college placement are generally not aligned. This misalignment is supported by multiple studies which examined the correlation between high school mathematics standards and the skills necessary for college success. These studies reported $25 \%$ to $40 \%$ of college mathematics objectives were not included in high school standards (Kendall et al., 2007; Shelton \& Brown, 2008). These findings were supported by the USDoE (2006) who 
reported: "The educational achievement levels of our young people who do complete high school are simply not high enough to allow them to succeed in college" (p. 8).

In particular, to receive a standard high school diploma in Virginia, the Virginia Department of Education require three credits of mathematics (8 VAC 20-131-50.B) which can be completed with Algebra I, Geometry, and Algebra II. However, the Virginia Department of Education in conjunction with two and four year colleges in the state created the "Mathematics Performance Expectations", a definition of the level of achievement needed by high school students to be prepared for success in college-level entry mathematics courses (VADoE, 2011). Almost 20\% (7 of 36) of these standards come from courses after Algebra II. Therefore, by policy, Virginia high schools are graduating students whom do not have skills the state has determined are needed to be successful in college-level mathematics.

Wilson (2008) provided an additional cause of the high numbers of students who require developmental mathematics as he concluded mathematics preparation was down across the country due to the use of calculators. The proscribed use of calculators is evidenced in Virginia as over half of the Virginia Standards of Learning for Algebra II explicitly reference using a graphing calculator and the VADoE provides resources to teachers on how to use the calculator to solve SOL questions (VADoE, 2011).

\section{Developmental Education in Virginia Community Colleges}

In Virginia community colleges, "developmental or preparatory programs shall be offered to prepare individuals for admission to the college transfer programs and the career/technical programs in the community college. These developmental programs shall 
be designed to develop the basic skills and understandings necessary to succeed in other community college programs" (VCCS, n.d., section 5.0.3). The most common developmental mathematics courses offered in the VCCS system over the time frame of this study are MTH 2 (Arithmetic), MTH 3 (Algebra I), and MTH 4 (Algebra II). These courses are offered by almost all of the 23 community colleges in Virginia and encompass almost all developmental students.

For self-evaluation purposes, the VCCS has authored or sponsored several studies which have reported on Virginia community college students. The VCCS (2011) reported on the fall 2006 cohort of first-time-in-college students who were placed in a certificate, diploma or associate degree program. Of the 23,542 students in this cohort, $14 \%$ were deemed college-ready by their scores on an incoming placement test, and $24 \%$ did not take the placement test. Therefore, $62 \%$ of students required developmental coursework by result of a placement test with $56 \%$ of students requiring mathematics developmental coursework. Roksa et al. (2009) conducted a similar examination of the 2004 cohort of first-time-in-college students in Virginia community colleges. The 2004 cohort had a similar number of students as did the 2006 cohort and Roksa et al. found the 2004 cohort had similar developmental placement of the 2006 cohort: $52 \%$ of the 2004 cohort of first-time-in-college students placed into developmental mathematics courses. Roksa et al. noted this number underestimated the proportion of students requiring remediation due to the number of students not taking the placement exam. The percentage of students whose test scores indicated a need for mathematics developmental coursework has remained steady from the 2005 cohort of first-time-in-college students 
through the 2009 cohort (VCCS, 2011). However, as Oudenhoven (2002) reported, the combination of increasing enrollments and constant proportion of students requiring developmental coursework, the number of students in the VCCS system requiring developmental coursework has increased over $30 \%$. According to calculations made from the Developmental Education Annual Report (VCCS, 2011) the number of students placed into developmental mathematics increased from 13,142 in 2005 to 17,574 in 2009 .

Developmental students in Virginia community colleges must successfully complete MTH 4 to enroll in a college-level mathematics course. Depending on their placement score, most community college students are initially placed into developmental courses MTH 2, MTH 3, or MTH 4 which are taken sequentially. The traditional path is for students to enroll in one mathematics course each semester until their sequence of courses is complete. Students are allowed to repeat a course two times, with the third attempt requiring permission from college administration. If a student fails to successfully complete a course three times they are no longer permitted to enroll in that course at that particular school, essentially ending their mathematics progressing at that college.

\section{Academic Success in Higher Education}

There are many different definitions of success in higher education found in the professional literature. The difference in defining developmental education creates problems when comparing research results. Success in higher education has been defined using program goals such as obtaining a degree or certificate after completing a series of courses (Attewell, Heil, \& Reisel, 2011; Bailey et al., 2005; Cooper, 2009; VCCS, 2009; 
Yates, 2010) or at the individual course level by completion of a developmental course (Kozeracki, 2002). Even when examining research which defined success at the course level differences exist in determining what successful completion of the course means. Success has been defined using a numeric value for grades (Alvarez, 2008; Byrd, 2004; Crews \& Aragon, 2004; Gonzales, 2007; Threadgill, 2009), by counting any grade except F as a success (Bahr, 2008; Fike \& Fike, 2007), and by counting grades which can typically be used to transfer credits to another institution, specifically an A, B, or C, as a success (Alcorta, 2009; Bauer, 2010; California Community Colleges, 2011a; DuBray, 2005; Germanna Community College, 2002; Gonzales, 2007; Linfante, 2002; Parmer \& Cutler, 2007; Roksa, et al., 2009; Silverman, 2010; VCCS, 2011).

The discussion on defining success in higher education is even more problematic for community colleges, particularly as general success in higher education is often viewed as the earning of a terminal degree. Bailey et al. (2005) wrote: "conventional models of institutional performance appear to work better for baccalaureate institutions than they do for two-year institutions" (p. iii) and suggested one reason is baccalaureate institutions have a much simpler and universal measure of success, a degree, than do twoyear colleges. They further stated "criticizing (community) colleges for low completion rates would reflect a misunderstanding of the mission of community colleges and the goals of their students" (p. 5).

\section{Success in Developmental Mathematics Courses}

More than $90 \%$ of responding community colleges in one study defined success for developmental students as successful completion of the developmental course 
(Kozeracki, 2002). Despite this agreement, the literature reports a wide range of success rates of developmental mathematics students. The percentage of students who successfully completed an individual developmental level course has been reported to be between 30\% and 75\% (Attewell et al., 2006; Bauer, 2010; DuBray, 2005; Germanna Community College, 2002; Illich et al., 2004; Kozeracki, 2002; Roksa et al., 2009; Sullivan, 2010; Waycaster, 2001; VCCS, 2011) with the majority of research reporting success rates between $50 \%$ and $60 \%$.

Succeeding in one developmental mathematics course is not the only hurdle many developmental students face. Students who require more coursework have a lower chance of completing the entire sequence of developmental courses (Bahr, 2007; Bailey et al. 2010; Roksa et al., 2009; Sullivan, 2010; VCCS, 2009). When the entire developmental program is considered rather than individual courses, 65 to $75 \%$ of students do not successfully complete their entire remedial program (Attewell et al., 2006; Bahr, 2008; Bailey et al.).

Completing the entire sequence of developmental coursework does not necessarily lead to success in college-level mathematics. Studies have shown fewer than $20 \%$ of developmental students ultimately pass a college level course (Alcorta, 2009; Bailey et al., 2010; DuBray, 2005) and the more remedial courses a student is required to take the less likely they ever are to achieve college-level mathematics success (Bahr 2007; Bailey et al.; VCCS, 2009). However, many times the non-completion of developmental coursework cannot be attributable to any institutional factor. Bailey et al. 
reported more students exit their developmental sequence due to not enrolling in the first or a subsequent course than due to withdrawing or failing a course

\section{Success of Developmental Students in College-Level Mathematics Courses}

Students who delay their developmental coursework have a lower likelihood of passing their first college-level course (Calcagno, 2007) and of succeeding in other coursework (Johnson \& Kuennen, 2004). However, once developmental students complete their developmental sequence and enroll in college-level courses, researchers have reported mixed results when comparing the success of developmental students to non-developmental students. Most research (Goldstein \& Perin, 2008; Waycaster, 2001), including studies of large, state-wide groups of students (Bahr, 2008; Calcagno, 2007; Martorell \& McFarlin, 2007; Roksa et al., 2009) reported developmental students succeeded in college-level mathematics courses at the similar rates as those students who did not require developmental coursework. The similarity in success between developmental and non-developmental students has also been seen in English courses (Goldstein \& Perin; Linfante, 2002; Moss \& Yeaton, 2006; Southard \& Clay, 2004). However, a few studies have found developmental students performed better in collegelevel courses (DuBray, 2005) and studies which found developmental students performed worse in college-level courses (Byrd, 2004; Germanna Community College, 2002;

Gonzales, 2007; Parmer \& Cutler, 2007).

Parmer and Cutler (2007) not only examined the final grade in college-level mathematics courses but also examined the grade on each exam during the semester. Whereas developmental students performed significantly worse than non-developmental 
students using the criteria of receiving an A, B, or C in the course, their grade on the first test of the semester was roughly the same as those students who did not require developmental work. Parmer and Cutler described the first test as largely a review of mathematical concepts students should have prior to enrolling in the course. They reported since the two groups performed about the same on a pre-course assessment that the groups were, in fact, on equal footing entering into the college-level course.

A growing body of work has examined outcomes of developmental students in college-level mathematics courses controlling for the demographic background of the student. Almost all of these studies (Attewell et al., 2006; Bettinger \& Long, 2005; Roksa et al., 2009) have found that developmental education does not negatively affect the success students achieve and many have found developmental education helps. Particularly, Bettinger and Long controlled for student characteristics in longitudinal study of community college students in Ohio and found developmental students were more likely to transfer to a four year institution, took more credit hours, and were no more likely to quit without a degree. Attewell et al. examined students from the 1988 National Educational Longitudinal Study and found that most of the gap in graduation rates reflected preexisting skill differences carried over from high school and had little to do with taking developmental courses. Linfante (2002) examined developmental English students and found that demographic information accounted for more of the variance in college-level English grades than did developmental status.

Bettinger and Long (2005) provided a descriptive explanation of the findings which show outcomes of developmental education are more affected by pre-existing 
student characteristics when they said: "It is clear from these results that students in remediation do not perform worse than similar individuals who do not enroll in remedial courses. Simple comparisons of the two groups mask this effect by comparing dissimilar students. When we compare students with similar characteristics, we find that remediation does not appear to have a negative effect. In fact, math remediation appears to improve some student outcomes." (p. 24)

\section{Persistence in the Community College}

Persistence, or the act of a student of remaining in a higher education program, is difficult to attribute to any one factor (Attewell et al., 2011; Braxton, Hirschy, \& McClendon, 2004), especially using an ex post facto format. This difficulty is particular relevant with research on community college persistence as students leave for many reasons, most beyond the control of the institution (Braxton et al.; Cohen \& Brawer, 2008). Among the reasons which are most commonly cited as contributing to a student not persisting in the community college are finances (Attewell et al.; Braxton et al.; Cohen \& Brawer), gender (Attewell et al.), ethnicity (Attewell et al.; Braxton et al.), and delaying entry (Arbona \& Nora, 2007; Attewell et al.; Bailey et al., 2005; Cohen \& Brawer; Johnson \& Kuennen, 2004). Additionally, an early exit from a community college may not even be a problem. Cohen and Brawer (2008) reported that a sizable percentage of students enrolled in community colleges are there for personal interest and Bailey et al. (2010) explained that initial college enrollment could be seen as an experiment for a student to determine their aptitude and desires for a college education. These students, during the initial coursework, evaluate whether the time, cost, effort, or 
benefits of college are worth persisting. Bailey et al. further stated a “(student's) early exit may suggest that they had gathered enough information about the barriers that they faced to decide that the cost would be too high. Without more information on these students and their motivations, it is difficult to make a judgment about (whether an early exit from college is a problem)" (p. 268).

The persistence rate of community college students has historically been very low. Approximately half of all community college students are not enrolled one year after beginning their studies (Braxton et al., 2004; Fike \& Fike, 2008; McIntosh \& Rouse, 2009; Moore, 2006) and less than $30 \%$ of community college students earn a degree or certificate (Bailey et al., 2005; McIntosh \& Rouse, 2009; Roksa et al., 2009; VCCS 2011). It is difficult to attribute the causes of student attrition. Particularly, noncompletion in a community college cannot be attributed solely to academic reasons (Attewell et al., 2011; Cohen \& Brawer, 2008). As an indication of the seriousness of the low level of degree attainment is to higher education the six main higher education associations in the United States (American Council on Education, American Association of Community Colleges, American Association of State Colleges and Universities, Association of American Universities, Association of Public and Land-Grant Universities, and National Association of Independent Colleges and Universities) will convene a commission to examine how to help students stay in college and succeed (Higher ed groups to examine college completion, 2011).

Another difficulty when discussing the persistence of students in higher education is the many varieties of ways in which researchers define persistence (McIntosh \& Rouse, 
2009). Persistence is often used to describe the act of a student receiving a degree, certificate, or some other terminal outcome (Cooper, 2009; Threadgill, 2005). This definition is particularly prevalent when discussing the persistence of students in fouryear institutions. This definition is more problematic with two-year and community colleges for students enter these institutions with many goals which may not include a terminal outcome (Bailey et al., 2005). To address the multitude of student goals in community colleges, some researchers define persistence as being enrolled in a subsequent semester (Lesik, 2007). However, there are many varieties of using enrollment in subsequent semesters in defining persistence. Some researchers use the time frame of one fall semester to the following spring semester, some of one fall to the next fall (Hawley \& Harris, 2005; Moore, 2006; VCCS, 2011), and yet others use different time periods (Lesik; Roksa et al., 2009). After terminal outcomes and enrollment in subsequent semesters, a third way researchers examine persistence is from a compilation of a particular number of earned college-level credits (Akst, 2007;

Calcagno et al., 2007a; Pelkey, 2011).

\section{Persistence of Developmental Students}

Most researchers have reported the persistence rates of developmental students, as defined by continued enrollment in the college, are greater than those of nondevelopmental students (Achieving the Dream, 2011; Bahr, 2007; Calcagno, 2007; Escobedo, 2007; Fike \& Fike, 2008; Lesik, 2007; Moore, 2006; Waycaster, 2001), with a number reporting no difference in persistence between the two groups (Roksa et al., 2009; Stewart, 2010; Threadgill, 2005). Particularly, Calcagno found the relationship 
between enrollment in developmental courses and persistence was causal. Although the persistence rate of developmental students is higher, Bahr reported even though mathematics developmental students do stay enrolled in the community college they generally do not attain college level mathematics skill.

Students who leave community college before a terminal outcome are generally labeled in statistical studies as having failed. However, ex post facto statistical research can not determine the entering educational goals of those students to understand whether leaving prior to obtaining a terminal outcome is considered failing by the student. The inability to understand the educational goal of a student who does not obtain a terminal degree creates a problem for researchers who define persistence by using graduation rates of community college students. Researchers have generally reported students who require developmental coursework graduate at much lower rates than students who do not require such coursework (Alliance for Excellent Education, 2011; Bailey, 2009; Martorell \& McFarlin, 2007; Yates, 2010), although there is evidence there is no difference between developmental and non-developmental students in credential attainment (Bahr, 2008).

Attewell et al. (2006) examined graduation rates of students using a different model. Whereas many studies report findings of student persistence to graduation using only developmental status, Attewell et al. used data from the National Education Longitudinal Study of 1988 to examine persistence to graduation using not only developmental status as a predictor variable but also demographic information. They found that most of the gap in graduation rates had little to do with remedial coursework 
but came from preexisting skill differences carried over from high school. In particular, they reported "taking remedial classes was not associated at all with lower chances of academic success, even for students who took three or more remedial courses" (p. 915). Tinto's Model of Student Integration

Vincent Tinto postulated that students who are socially integrated into a school have a much higher likelihood of persisting in their education (Tinto, 1993). This theory has been the subject of a large body of research in four-year residential institutions and has formed the basis for many of the orientation programs conducted by four year residential universities for freshmen conducted in the days before classes begin in the fall semester. However, Tinto questioned whether his theory applied to commute schools such as community colleges. Researchers have recently found persistence can be increased by social integration similar to findings from four year schools (Attewell et al., 2011; Cohen \& Brawer, 2008; DuBray, 2005; Hawley \& Harris, 2005; Karp et al., 2010; Tinto, 1997). Integration in the community college generally occurs academically, and arises from the classroom and faculty, counselors, and other individuals on campus (Bharath, 2009; Capps, 2010) rather than from social situations as in four-year colleges. In many community colleges, and particularly in most community colleges in Virginia, developmental courses meet for longer periods of time than do college level courses and employ more student centered teaching approaches. These smaller classes and additional attention students receive may be keys to retaining developmental students (Waycaster, 2001) by integrating them in academic ways. 
Socially integrating community college students may be one way to help retain those students, particular for students who are not prepared for college level work. Integrating students in the school has been found to be a significant factor among students who successfully completed their developmental coursework (DuBray, 2005). Successful completion of a developmental course and student retention has been found to be positively correlated (Duranczyk \& Higbee, 2006; Fike \& Fike, 2008). Social integration theory could explain this relationship as developmental instructors spend more time in instructional activities than college level instructors (Kisker \& Outcalt, 2005), give more attention to the student (Waycaster, 2001), create student-centered pedagogies which help students interact with each other and form social networks (Karp et al., 2010; Tinto, 1997). These techniques, common to developmental classrooms, help create an atmosphere where students can feel connected and integrated with the school (Lesik, 2007) and have been suggested as reasons developmental students persist at higher rates than non-developmental students.

Some researchers, however, have argued against the appropriateness of using Tinto's social integration theory to describe the experiences of community college students. Bailey et al. (2005) reported even though there is consensus that social and academic integration positively affects retention at baccalaureate institutions, these findings distort knowledge about community college students. Particularly, Bailey et al. suggested that new and different models be developed which particularly reflect the community college student and institutional factors which are present in community colleges. Jefferson (2010) examined underprepared students at a two-year college and 
found support from instructors, particularly in developmental courses, helped motivate students to persist in their studies, but more important to their persistence was their own determination and other external motivations. Taylor (2009) found similar results to Jefferson and reported no significant relationships between academic integration and persistence among developmental students. Braxton et al. (2004) argued that Tinto's integration theory may not even be valid for four year residential schools, but the application of the theory to commuter colleges should be abandoned.

\section{Race and Ethnicity of Students in Community Colleges and Developmental Mathematics}

Approximately one third of community college students in the United States are non-White (Cohen \& Brawer, 2008; McIntosh \& Rouse, 2009; Provasnik \& Planty, 2008 ) and this percentage is much higher in certain areas of the country (California Community Colleges, 2011b; Cohen \& Brawer; DuBray, 2005, FLDoE, 2011b). Examining college experiences of non-White students is particularly important at the community college level since a higher proportion of students are non-White at the community college than in four year universities (Cohen \& Brawer; Fike \& Fike, 2008; McIntosh \& Rouse; Provasnik \& Planty). Whereas students of all backgrounds require developmental coursework, this issue is more prevalent for non-White students (Martorell \& McFarlin, 2007), particularly in developmental mathematics courses (Alliance for Excellent Education; Bettinger \& Long, 2005; Stewart, 2010; Zhu \& Polianskaia, 2007). In particular, Black students are significantly more likely to enroll in developmental courses than are White students with similar backgrounds (Attewell et al., 
2006; FLDoE, 2011 a; Gonzales, 2007). One possible reason Black students require developmental courses at higher rates than other racial and ethnic groups is Black high school students have lower access to high-quality secondary education than their White counterparts (Alliance for Excellent Education, 2011). Bettinger and Long examined 13,000 community college students in Ohio and found $55 \%$ of White students were placed in developmental courses and over $75 \%$ of Black and Hispanic students were. The VCCS (2011) examined over 14,000 first-time-in-college students and found that $45 \%$ of White students took a developmental course in their first year and $56 \%$ of nonWhite and $63 \%$ of Black students did so. Cho (2011) studied students from over 100 community colleges taking part in the Achieving the Dream grant program and found over half of students referred to developmental education were Black or Hispanic.

\section{Academic Success of Students Based on Race and Ethnicity}

Not only are non-White students over-represented in developmental mathematics but these students are also generally less successful than their White peers. White students in community colleges are not only more likely to complete their developmental courses (Bettinger \& Long, 2005) and enroll in college-level courses (Cho, 2011) but also outperform other ethnicities in those courses (Alvarez, 2008; California Community Colleges, 2011a; Fike \& Fike, 2007). Black students have been found to have particularly low success in developmental courses (Bailey et al., 2010; Dahlstrom, 2005; DuBray, 2005; Roksa et al., 2009; Sullivan, 2010). Whereas the majority of research findings indicated non-White students are less successful than their White counterparts 
there are a number of studies (Corey Legge, 2010; Gonzales, 2007) which found ethnicity was not significantly related to course success.

However, even though race and ethnicity has been found to have a significant relationship with higher grades the practicality of this relationship has been questioned. Alvarez (2008) found there was a significant relationship between ethnicity and higher English Composition grades; however, this relationship accounted for less than one percent of the variability in the grades. Even though Alvarez found a significant relationship that relationship did not explain very much of the grade difference. Cooper (2009) supported this finding by reporting whereas White students graduated at higher rates than non-White students, the effect size was low.

\section{Persistence of Students Based on Race and Ethnicity}

Non-White students in both two year and four year colleges have been reported to graduate at lower rates than do White students (Attewell et al., 2006; Bailey et al., 2005; Cooper, 2009, USDoE, 2006). Particularly, Attewell et al. reported being Black is a causal factor which reduces the chance of graduating from a two-year college.

Bailey et al. (2010) reported that Black community college students had significantly lower odds of passing developmental coursework than White students and this effect was particularly low for students needing more than one developmental course. The lower persistence for non-White students has been reported by numerous other researchers (Bailey et al., 2005; Bailey et al., 2010; Braxton et al., 2004; Gonzales, 2007). Boylan, Bonham, and Tafari (2005) argued that minority retention should be a major goal 
of developmental education since such a high proportion of developmental students are minority students.

A small number of researchers have reported that race and ethnicity is not a significant predictor of persistence, either in fall-to-fall persistence (Fike \& Fike, 2008; Moore, 2006) or in persistence to earning 45 credits (Pelkey, 2011) whereas Hawley \& Harris (2005) found being Black or Hispanic was among the strongest predictors of fallto-fall persistence.

\section{Gender of Students in Community Colleges and Developmental Mathematics}

Women outnumber men in higher education today (Provasnik \& Planty, 2008; VCCS, 2011). Currently, close to $60 \%$ of community college students are female (Bailey et al., 2005; Cohen \& Brawer, 2008; DuBray, 2005; Provasnik \& Planty). Men generally perform better than women on mathematical assessments (James, 2007), and this is supported by the number of students who require developmental mathematics courses. A greater proportion of women require developmental courses than men (Bettinger \&Long, 2005; Byrd, 2004; FLDoE, 2011 a; Lynch-Newberg, 2010; VCCS, 2011).

\section{Academic Success of Students Based on Gender}

Whereas it is more likely that a female community college student will require developmental coursework (Bettinger \& Long, 2005) once students are in developmental courses females find a greater level of success than their male counterparts (Cho, 2011; Corey Legge, 2010; Fike \& Fike, 2007; Gonzales, 2007; Roksa et al., 2009). Success is measured by being more likely to pass developmental courses (Bettinger \& Long; Roksa et al.; Sullivan, 2010) and by being more likely to progress through their full 
developmental sequence (Bailey et al., 2010; Cho). The higher success rates for female students not only occur in developmental courses but in college-level courses as well (Alvarez, 2008; Kolajo, 2004; Roksa et al.). One possible cause for the disparity in success rates is men tend to delay taking developmental courses more than women do (Johnson \& Kuennen, 2004).

\section{Persistence of Students Based on Gender}

Women graduate from both two-year and four-year colleges at higher rates than do men (Arbona \& Nora, 2007; Bailey et al., 2005; Buchmann \& DiPrete, 2006; Cooper, 2009; Gonzales, 2007). Buchmann and DiPrete explained the difference in graduation rates between men and women is due to an inherent advantage females have in academics, a difference which the authors reported is not fully realized until college. The authors believe the difference in graduation rates between female and male students is becoming more pronounced now "from a combination of declining gender discrimination and women's growing interest in possessing autonomous resources" (p. 535) leading to increased success in both the labor and marriage market.

The literature which examines persistence defined as continued enrollment in the college based on gender is limited. The literature which exists has reported that gender is not a significant predictor of persistence whether for all students (Moore, 2006) or when comparing developmental and non-developmental students (Stewart, 2010) or when only examining developmental students (Pelkey, 2011).

\section{Age of Students in Community Colleges and Developmental Mathematics}

The age of students in community colleges is higher than the traditionally aged 
cohort of students in four year universities (Cohen \& Brawer, 2008; McIntosh \& Rouse, 2009). Non-traditionally aged students have been defined in the literature using different ranges. Some research (Cooper, 2009; Kozeracki, 2002), particularly that of the VCCS (VCCS, 2011), define non-traditionally aged students as 23 years of age or older. More commonly in research, non-traditional age is defined as 25 years of age or older (Alvarez, 2008; Lynch-Newberg, 2010; Roksa et al., 2009; Silverman, 2010). Regardless of the age range for which non-traditional students are defined, the percentage of nontraditionally aged students in the community college is reported to be approximately $50 \%$ (Cohen \& Brawer, 2008; DuBray, 2005; Provasnik \& Planty, 2008). A major part of the mission of community colleges is to provide workforce training, continuing education, and community services to adult students (Ayers, 2002; Cohen \& Brawer, FLDoE, $2011 \mathrm{~b})$, which provides a compelling reason to study the characteristics and success of non-traditional aged students.

The professional literature is mixed when reporting the age of student who is most likely to require developmental course work. Both older students (FLDoE, 2011a) and younger students (Cho, 2011; Gonzales, 2007) have been reported as more likely to need developmental coursework. Kozeracki (2002) reported that developmental students are just as likely to be older than 22 than 22 or younger.

\section{Academic Success of Students Based on Age}

Researchers have reported older students succeed at higher rates in higher education than do their younger counterparts (Alvarez, 2008; California Community Colleges, 2011a; Kolajo, 2004; Lynch-Newberg, 2010). Byrd and Macdonald (2005) 
examined older, first-generation community college students and found even though academic skills are important in the success of students in college, "time management, goal focus, and self-advocacy emerged as more important... These skills, it seems, are woven into or emerge out of life experience more than do academic skills" (p. 32). Thus, older students found more success in their college work due to skills they obtained from their life experiences.

Age continues to differentiate the success rates of students in individual developmental education courses. The majority of research has reported older students are more likely to successfully complete their developmental courses than are traditionally aged students (Alvarez, 2008; Byrd \& Macdonald, 2005; Calcagno et al., 2007a; Cho, 2011; Dahlstrom, 2005; DuBray, 2005; Fike \& Fike, 2007; Gonzales, 2007; Roksa et al., 2009). Byrd and Macdonald provided a possible explanation of the difference in success rates between traditionally and non-traditionally aged students: "younger first generation college students might be particularly at risk for college readiness, given that life experience and being older contributed to the skills of older first-generation students" (p. 33). Another possible explanation was provided by Johnson and Kuennen (2004) who reported younger students delay taking their developmental courses more than older students.

A number of studies have reported different findings of the success of community college students based on age. Corey Legge (2010) found that age was not related to success in a developmental course which made use of a supplemental instructor and Bailer (2006), Miglietti and Strange (1998), and Sullivan (2010) all found age was not 
related to developmental course grades. Bettinger and Long (2005) found younger students were more likely to complete their developmental sequence than were older students. This result may be due to younger students being more familiar with the requirements of academia, a position supported by Biegel (2009) who reported developmental students who enrolled in community college within two years of graduating from high school were twice as likely to have been successful in college-level courses as students who delayed enrollment in community college.

\section{Persistence of Students Based on Age}

The literature presents mixed results of graduation rates of community college students based on age. Cooper (2009) examined developmental students and Calcagno, Crosta, Bailey, and Jenkins (2007b) examined all students with both reporting traditionally aged students were more likely to graduate. However, Calcagno et al. (2007a) examined developmental students and found older students were more likely to graduate than traditionally aged students.

The current literature is limited and inconclusive on the persistence of students among different age groups. Graybeal (2007) examined research from the 1990s and described conflicting findings in that research. More recently, research has seemed to find persistence is negatively impacted by age. Specifically, older students have been found to have lower persistence in higher education than do younger students (Akst, 2007; Fike \& Fike, 2008; Moore, 2006). They are also less likely to persist in a developmental sequence of courses than traditionally aged students (Bailey et al., 2010). 
These findings are not universal, however, as Pelkey (2011) found that age was not significant in developmental students reaching 45 earned credits.

\section{Summary}

This chapter has presented the current theoretical and empirical research on relevant topics to this study on community college success and persistence. Specifically, literature was examined and presented on the topics of developmental education, student success, student persistence, and differences in developmental education, success, and persistence based on a student's gender, age, and race and ethnicity. This review has provided the importance and timeliness of examining these variables in conjunction with developmental education. The next chapter will provide the methodology which will be used to answer the research questions. 


\section{CHAPTER III}

\section{METHODOLOGY}

This chapter will outline the methodology and procedures which were used in this study, including the context or setting of the study, the variables, the data collection procedures, and the data analysis procedures.

The purpose of this quantitative study was to examine the effect of age, gender, and race and ethnicity together with developmental mathematics status on student's persistence to a second year and academic performance in the student's first college level mathematics course in Virginia community colleges. This study utilized the data reported by the Virginia Community College System in: "Developmental Education Annual Report: Tracking the Fall 2006 Cohort and Five-Year Historical Trends" (VCCS, 2011).

This study was guided by the following research questions:

1. Are there moderating variables on developmental mathematics status in determining the success of Virginia community college students in their first college-level mathematics course?

a. Does student race and ethnicity moderate the effects of developmental mathematical status on the success of Virginia community college students in their first college-level course?

b. Does student gender moderate the effects of developmental mathematical status on the success of Virginia community college students in their first college-level course? 
c. Does student age moderate the effects of developmental mathematical status on the success of Virginia community college students in their first college-level course?

2. Are there moderating variables on developmental mathematics status in determining the fall-to-fall persistence of Virginia community college students?

a. Does student race and ethnicity moderate the effects of developmental mathematical status on the fall-to-fall persistence of Virginia community college students?

b. Does student gender moderate the effects of developmental mathematical status on the fall-to-fall persistence of Virginia community college students?

c. Does student age moderate the effects of developmental mathematical status on the fall-to-fall persistence of Virginia community college students?

3. To what extent do developmental status, gender, age, race and ethnicity, and interactions between developmental status and age, developmental status and gender, and developmental status and race and ethnicity account for success of Virginia community college student in their first college-level mathematics course? 
4. To what extent do developmental status, gender, age, race and ethnicity, and the interaction between developmental status and age, developmental status and gender, and developmental status and race and ethnicity account for the fall-to-fall persistence of Virginia community college students?

\section{Setting}

The Virginia Community College System was created in 1966 "for the establishment, control, and administration of a statewide system of publicly supported comprehensive community colleges" (Va. Code $\S 23-215,2004)$. As a result of this centralized system of community colleges in Virginia, all community colleges in the state operate using the same policies, course descriptions, degree programs, and structure (Virginia Community College System, n.d.). Additionally, each community college offer courses from a master file, both college-level and developmental. Each course offered, regardless of which individual college offers the course, uses the same course objectives. The uniformity of course content across all 23 community colleges in Virginia allowed this study to compare student data independent of the particular community college that student was enrolled.

Whereas the course content is the same throughout the Virginia Community College System there exists a great diversity within the student body of the colleges. Virginia has one of largest and several of the smallest community colleges in the country in terms of number of students served. Virginia has community colleges in large, urban areas and in small and isolated rural areas. Vocations of citizens living in the service area of Virginia's community colleges include farming, business, education, military, and 
manufacturing. The Virginia Community College System is comprised of students whose varied demographic composition is representative of community colleges from across the United States, thereby creating the ability to generalize findings from this study to community college students outside of Virginia. Persistence and academic success are affected by a large number of institutional factors such as institutional size, community size, per capita income of the community college service regions, and college policies, and individual factors such as income, high school course loads, high school grades, social economic status, and the desired outcome of higher education. Sampling from all twenty-three community colleges will provide a diverse sample where the effect of these untested factors will be minimized.

This study utilized ex post facto data to examine students who first enrolled in a Virginia community college during the fall 2006 semester and examined records for those students through the spring 2011 semester. The time frame of this sample was chosen to allow data to be collected from a five-year period to allow students whose first mathematics course is developmental to have time to enroll in a college-level course for comparisons.

\section{Variables}

Dichotomous variables were created for all factors to be examined in this study. The predictor variables which were used throughout this study are: developmental status, age, gender, black, other ethnicity, and the interaction variables developmental*age, developmental* gender, developmental*black, and developmental*other. The criterion variables which were used in this study are persistence and success. 
For research questions one and three the predictor variables were developmental status, gender, age, black, other ethnicity, and the interaction variables developmental ${ }^{*}$ gender, developmental ${ }^{*}$ age, developmental*black, and developmental*other. The criterion variable was academic success as defined by obtaining a transferable grade of $\mathrm{C}$ or above.

For research questions two and four the predictor variables were developmental status, gender, age, black, other ethnicity, and the interaction variables developmental*gender, developmental*age, developmental*black, and developmental ${ }^{*}$ other. The criterion variable was persistence as defined as attendance in the college in the fall 2007 semester.

\section{Subjects}

The population for this study was all community college students in the state of Virginia. A purposeful sample was taken consisting of all students who first enrolled in a Virginia Community College during the fall 2006 semester and who enrolled in a mathematics course during the five year time frame of the study. This sample provided the most current data allowing the opportunity to follow students through five years and descriptive statistics have already been reported on this data by the VCCS (VCCS, 2011). Following a group of students over a five year period not only allowed persistence to a second year to be determined but also allowed enough time for academic performance in college-level courses to be determined for most students.

For research questions one and three, this study aimed to determine the effect of developmental status in conjunction with other variables on the success of the student in 
their first college-level course. For that reason, students who did not take a college-level mathematics course during the five-year time period of this study were removed from the sample used in the model created to answer these questions. These students were included in the sample for the model to answer research questions two and four.

For research questions two and four, this study aimed to determine the effect of developmental status in conjunction with other variables on persistence to a second year of attendance at the college. For that reason, students who did not take a mathematics course during their first semester were removed from the sample used in the model created to answer these questions. These students were included in the sample for the model to answer research questions one and three.

\section{Data Collection Procedure}

This study was submitted to the Darden College of Education Human Subjects Review Committee which deemed the study to be exempt from the Human Subjects Review Board. The study was then proposed to the Academic Services and Research Department at the Virginia Community College System (VCCS) where it was approved.

Ex post facto data were gathered from the Academic Services and Research department of the Virginia Community College System during the spring 2012 semester. One advantage of a centralized community college system as exists in the state of Virginia is the Office of Institutional Research of the VCCS collects data from each of the 23 Virginia community colleges. This simplifies the compilation of data from across all community colleges in the state and provides the opportunity to conduct research with a state-wide sample. This study also used a previously collected sample which simplified 
the data collection procedure. The VCCS has reported descriptive statistics on the 2006 first-time-in-college students based on developmental status (VCCS, 2011). This study extends the knowledge from that report as the current study examined the data using a statistical level of significance (.05) and examined differences based on age, gender, and race and ethnicity. Additionally, the current study determined whether student age, gender, or race and ethnicity moderates the effects of developmental mathematics status on student success or persistence.

The following data were collected for each student who first enrolled in a Virginia community college during the fall 2006 semester: age, gender, race and ethnicity, enrollment status for each semester from fall 2006 through spring 2011, all mathematics courses in which the student had enrolled, and grades for each mathematics course in which a student had enrolled. These data were collected using pseudo-IDs for each student to allow compilation of the data on a per-student basis while preserving student confidentiality.

The sample was examined for the semester of the first mathematics course taken. Students who were not of either traditional or non-traditional college age, specifically those students aged 16 and younger, were removed from the sample. Students who did not take a mathematics course during the first semester, fall 2006, were marked for removal for the sample used to answer research questions two and four (fall-to-fall persistence) by coding those students as a missing variable for the criterion variable persistence. Students who did not take a college-level mathematics course during the five-year study period were marked for removal for the sample used to answer research 
questions one and three (success in college-level mathematics course) by coding those students as a missing variable for the criterion variable success. Dichotomous variables representing non-traditional age, female gender, black race and ethnicity, other race and ethnicity, developmental status, persistence, and success were then created for each student.

The variable age was coded with a 1 to represent non-traditionally aged students (23 and older) and with a 0 to represent traditionally aged college students (17 to 22 ). The variable black was coded with a 1 to represent a Black student and with a 0 to represent a non-Black student. The variable other was coded with a 1 to represent a nonWhite, non-Black student and with a 0 to represent a Black or White student. Gender was coded with a 1 to represent a female student and with a 0 to represent a male student. Developmental status was coded with a 1 to represent a student whose first mathematics course was developmental and a 0 to represent a student whose first mathematics course was college level. Persistence was coded with a 1 to represent a student who was enrolled in the college during the fall 2007 semester and a 0 to represent a student not enrolled in this semester. Students who did not take a mathematics course in the fall 2006 semester had the variable persistence coded as a missing variable to eliminate that record from the model for persistence. Success was coded with a 1 to represent a student who received an $\mathrm{A}, \mathrm{B}$, or $\mathrm{C}$ in their first college level course and a 0 to represent students who received a D, F, or W in their first college level course. Students who did not enroll in a college-level mathematics course had the variable success coded as a missing variable to eliminate that record from the model for success. Meyers, Gamst, and 
Guarino (2006) recommended assigning the coding 1 to represent the presence of some attribute as was done in this study. This group is also called the target group.

\section{Data Analysis}

Data from all students who first enrolled in a Virginia community college in the fall 2006 semester were gathered. SPSS version 19 was used to analyze the data. A preliminary data screen was performed using frequency tables to examine for any missing or implausible values.

Data were examined to identify students who were 16 years of age or less. These students were removed from the sample.

The dichotomous variables developmental status, persistence, age, gender, black, other ethnicity, and success were then created for each student using the values described in the data collection section.

Four product variables were created to determine if age, gender, or race and ethnicity moderates developmental status in determining the success or persistence of students. These variables were: developmental*age, developmental*gender, developmental*black, and developmental*other. These variables were calculated by multiplying the values for each individual variable for each student. Thus, the value for each of these product variables was 1 if the student exhibited the characteristics of both main variables, and 0 otherwise.

Descriptive statistics and marginal distributions were computed and reported in table form. Counts were reported for each variable. Counts were reported for the variables success and persistence with subcategories developmental, age, gender, and 
ethnicity.

Analysis of the models created throughout this study was performed using binary logistic regression. A binary logistic regression can be used to identify variables associated with being in one condition or another, particularly with an output variable which has only two possible outcomes (Meyers et al., 2006). This statistical technique is the most appropriate for several reasons. If a least squares method were used, the dichotomous criterion variable would violate the normality and equal variance assumptions (Meyers et al.; Pampel, 2000). Additionally, other types of regression methods, such as linear or quadratic, could result in values for the criterion variable less than zero or greater than one (Pampel). The result of the binary regression procedure represents the probability the criterion variable occurs (Meyers et al.).

A binary logistic regression was performed to answer the research questions. Two regression models were created. One model used success as its criterion variable; the other used persistence as its criterion variable. Both regressions used the same predictor variables: developmental, gender, age, black, other ethnicity, and the product variables developmental*gender, developmental*age, developmental*black, and developmental*other.

Statistical significance of each model was examined using an Omnibus Test of Model Coefficients. This test examined the overall model and determined if the predictor variables improved prediction of the criterion variable (Meyers et al., 2006). A significance value of less than .05 indicated the model did improve prediction of the criterion variable over a constant-only model. A Hosmer and Lemeshow Test was 
conducted to assess whether the predicted probabilities from the model matched the observed probabilities (Meyers et al.). A significance value of greater than .05 indicated the predicted probability of the criterion variable accurately matched the observed probabilities. Finally, a Wald Test was performed. This test examined the statistical significance of the unique contribution of each coefficient in the model (Meyers et al.). Any predictor variable which had a significant Wald statistic, less than .05 , provided a significant predictor of the criterion variable. Significance of the product variable indicated that a main predictor, age, gender, or race and ethnicity, moderated the effect of developmental status on the criterion variable.

Using the logistic regression results, a classification table was reported which indicates the overall accuracy of the prediction of the model, and an adjusted odds ratio was calculated and reported for each model. The regression coefficients, Wald statistics, significance level, adjusted odds ratio, and $95 \%$ confidence intervals for the adjusted odds ratio for the model for each criterion variable was presented in table form.

Using the logistic regression results, the predicted probabilities of success and persistence were computed using the antilog of the regression equation. The predicted probabilities for each combination of demographic characteristics were presented in appendices.

\section{Summary}

Chapter III has provided the methodology used to answer the research questions, namely are there differences based on developmental status, gender, age, and race and ethnicity in the success and persistence of Virginia community college students. A 
detailed description of the variables to be used in the study, setting, and subjects were provided along with the procedure used to collect data. Finally, the statistical procedure, logistic regression, was presented and the process by which logistic regression would be used to answer the research questions was given.

The next two chapters will present the findings and conclusions. Chapter IV will present the findings from this study. Tables and narratives will be used to present the data obtained from the sample. Chapter V will then summarize the study and will provide discussion of the findings in context with previous literature. Chapter $\mathrm{V}$ will also provide implications of the findings for community college practitioners and will suggest areas for future research which have been suggested from this study. 


\section{CHAPTER IV}

\section{FINDINGS}

The purpose of this study was to determine the effects of developmental mathematics status, gender, race and ethnicity, and age on the success and persistence of Virginia Community College students. This study utilized the 2006 cohort of First-Timein-College students from all 23 community colleges in Virginia. The criterion variables used in this study were persistence and success. This study considered persistence to be fall-to-fall persistence; students were determined to have persisted if they were enrolled in the college during the fall 2007 semester, one year after their initial enrollment. Success was defined as obtaining a transferable grade in a college-level mathematics course. Transferable grades include an A, B, or C. The main predictor variable was the developmental status of the student. This variable was coded 1 for students whose first mathematics course was a developmental one. Other predictor variables used in the study were all dichotomous and were Non-traditional age (students ages 23 or older), Gender (female), Black, Other_ethnicity (non-White and non-Black students), and the interaction variables Developmental*NTage, Developmental*Gender, Developmental*Black, and Developmental ${ }^{*}$ other.

The results of the research are presented in this chapter. The findings include tables providing descriptive statistics and the results of the predictive models. The statistical procedures performed in the predictive analysis for this study include a Chi Square test to determine the overall model fit, adjusted odds ratios to determine the effect 
of each predictor variable, and a Wald test to determine the relative strength of each predictor variable.

\section{Data Screening}

There are a total of 23,542 students who were identified as First-Time-in-College students at one of the 23 Virginia community colleges for the fall 2006 semester. This total also includes students who first enrolled in a Virginia community college during the summer 2006 semester. Data for this study were reported by the VCCS in two separate files: one included demographic information and the second provided course and grade information. Data in the two files were reported with common pseudo-ID numbers which were used to merge the two files. Students who never enrolled in a mathematics course $(n=6102)$ were removed from the sample. Students who were under age 17 at time of enrollment $(n=105)$ were removed from the sample as they did not fall into either traditionally or non-traditionally aged college student age ranges which were used in the current study. There were no missing data for any student for any variable.

Dichotomous variables representing the inclusion of a student in the following categories were created: Developmental, Non-traditional age, Black race and ethnicity, non-Black and non-White race and ethnicity, and Female. Students who exhibited these characteristics were coded with a 1 ; otherwise each variable was coded with a 0 . The dichotomous variable success was created and coded with a 1 for students who received an $\mathrm{A}, \mathrm{B}$, or $\mathrm{C}$ in their first college-level mathematics course. Students who received a D, F, or W in their first college-level mathematics course were coded with a 0 . Students who never enrolled in a college-level mathematics course were coded with a 9 which was 
identified as a missing variable for the predictive models. The dichotomous variable persistence was coded with a 9 for students who did not take a mathematics course during the first semester (FA2006 or SU2006), and this value was identified as a missing variable for the predictive models. For students who did take a mathematics course during their first semester, the variable persistence was coded with a 1 for those students who were enrolled during the fall 2007 semester, and a 0 for those students who were not enrolled in the fall 2007 semester. To determine if there were moderating variables on developmental status in the success or persistence of students the interaction variables developmental*NTage, developmental*gender, developmental*black, and developmental*other were created.

\section{Descriptive Statistics}

Students in the sample are predominately female (53.6\%), traditional college age (85.2\%), White (62.9\%), and were identified as developmental students by virtue of their first mathematics course being a developmental one (58.4\%). Descriptive statistics on these variables are provided in Table 1.

The criterion variables success and persistence were created. The variable success represents the success or non-success of students who took a college-level mathematics course between the fall 2006 semester and the spring 2011 semester. Descriptive statistics on the success of the sample are provided in Table 2. The variable persistence represents the enrollment or non-enrollment during the fall 2007 semester of students who were enrolled in any mathematics course during the summer or fall 2006 semesters. Descriptive statistics on the persistence of the sample are provided in Table 3. 
Table 1

Descriptive Statistics for Sample Demographic Information

\begin{tabular}{llcc}
\hline Variable & Categories & Frequency $(n)$ & Percent (\%) \\
\hline Gender & Male & 8044 & 46.4 \\
& Female & 9291 & 53.6 \\
Age & $17-22$ & 14765 & 85.2 \\
& 23 and older & 2570 & 14.8 \\
Ethnicity & White & 10902 & 62.9 \\
& Black & 3504 & 20.2 \\
& Other & 2929 & 16.9 \\
& Developmental & 10120 & 58.4 \\
\hline
\end{tabular}

Table 2

Success in the First College-Level Mathematics Course

Success Status

Frequency $(n) \quad$ Percent (\%)

Succeeded

6962

40.2

Did not Succeed

4290

24.7

Did not Attempt

6083

35.1 
A cross tabulation was created for the criterion variables success and persistence to indicate the numbers of students who succeeded and persisted based upon the age, gender, race and ethnicity, and developmental status of the student. The descriptive statistics from the cross tabulation for the success of students are provided in Table 4. The descriptive statistics from the cross tabulation for the persistence of students are provided in Table 5 .

\section{Predictive Models}

The purpose of this quantitative study was to examine the effect of age, gender, and race and ethnicity together with developmental mathematics status on student's persistence to a second year and academic performance in the student's first college level mathematics course in Virginia community colleges. To answer these questions, binary logistic regressions were performed to identify to what extent age, gender, race and

\section{Table 3}

Persistence to the Fall 2007 Semester

Status

Frequency (n) Percent (\%)

Persisted 7698

Did not Persist

5330

30.7

Not enrolled in Math during Fall 2006

4307

24.8 
Table 4

Crosstabs for Success and Demographic Variables

\begin{tabular}{|c|c|c|c|}
\hline \multirow[t]{2}{*}{ Variable } & \multirow[t]{2}{*}{ Category } & Succeeded & Did not Succeed \\
\hline & & $\%$ & $\%$ \\
\hline \multirow[t]{2}{*}{ Age } & $17-22$ & $5889(59.9)$ & $3944(40.1)$ \\
\hline & 23 and older & $1073(75.6)$ & $346(24.4)$ \\
\hline \multirow[t]{2}{*}{ Gender } & Female & $3819(66.2)$ & $1952(33.8)$ \\
\hline & Male & $3143(57.3)$ & $2338(42.7)$ \\
\hline \multirow[t]{3}{*}{ Ethnicity } & White & $4763(63.2)$ & $2777(36.8)$ \\
\hline & Black & $875(54.1)$ & $741(45.9)$ \\
\hline & Other & $1324(63.2)$ & $772(36.8)$ \\
\hline \multirow[t]{2}{*}{ Developmental Status } & Developmental & $2428(60.1)$ & $1609(39.9)$ \\
\hline & Non-Developmental & $4534(62.8)$ & $2681(37.2)$ \\
\hline
\end{tabular}

ethnicity, developmental status, and interactions between developmental status and age, race and ethnicity, and gender accounts for the success and persistence of Virginia community college students.

\section{Research Question 1: Moderating Variables on Success}

To answer research question 1 , a binary logistic regression was performed with the criterion variable success and predictor variables gender, NTage, black, other 
ethnicity, developmental, and the interaction variables developmental*gender, developmental*NTage, developmental*black, and developmental*other. Examining the results of the Wald test on the interaction variables indicate that neither gender $(p=.610)$ nor ethnicity (black $p=.682$, other $p=.359$ ) moderates the effects of developmental mathematics status on the success of Virginia community college students in their first college-level course. The Wald test does indicate that age moderates the effects of

Table 5

Crosstabs for Persistence and Demographic Variables

\begin{tabular}{|c|c|c|c|}
\hline Variable & Category & Succeeded & Did not Succeed \\
\hline & & $\mathrm{N} \quad \%$ & $\mathrm{~N}$ \\
\hline \multirow[t]{2}{*}{ Age } & $17-22$ & $6849(60.3)$ & $4517(39.7)$ \\
\hline & 23 and older & $849(51.1)$ & $813(48.9)$ \\
\hline \multirow[t]{2}{*}{ Gender } & Female & $4077(59.9)$ & $2730(40.1)$ \\
\hline & Male & $3621(58.2)$ & $2600(41.8)$ \\
\hline \multirow[t]{3}{*}{ Ethnicity } & White & $4955(60.0)$ & $3303(40.0)$ \\
\hline & Black & $1405(51.3)$ & $1335(48.7)$ \\
\hline & Other & $1338(65.9)$ & $692(34.1)$ \\
\hline \multirow[t]{2}{*}{ Developmental Status } & Developmental & $4558(56.9)$ & $3457(43.1)$ \\
\hline & Non-Developmental & $3140(62.6)$ & $1873(37.4)$ \\
\hline
\end{tabular}


developmental status on the success of Virginia community college students $(p=.008)$.

The adjusted odds ratio indicates that a non-traditionally aged developmental mathematics student is $29.9 \%$ less likely to be successful than other groups. Table 6 presents the regression coefficients $(B)$, the Wald statistics, significance levels, adjusted.

Table 6

Logistic Regression Results for Success

$95 \% \mathrm{CI}$ for $\operatorname{Exp}(B)$

Variable

$B \quad$ Wald Significance

$\operatorname{Exp}(B) \quad$ Lower Upper

\begin{tabular}{lcccccc}
\hline & & & & & & \\
Developmental & -.132 & 3.915 & .048 & .876 & .768 & .999 \\
Gender & .377 & 57.481 & .000 & 1.458 & 1.323 & 1.607 \\
NTage & .955 & 103.278 & .000 & 2.599 & 2.162 & 3.125 \\
Black & -.495 & 40.729 & .000 & .610 & .524 & .710 \\
Other Ethnicity & .024 & .145 & .703 & 1.025 & .904 & 1.162 \\
Dev*Age & -.356 & 7.082 & .008 & .701 & .539 & .911 \\
Dev*Gender & .042 & .260 & .610 & 1.043 & .887 & 1.226 \\
Dev*Black & .047 & .168 & .682 & 1.048 & .837 & 1.312 \\
Dev*Other & -.100 & .841 & .359 & .905 & .731 & 1.120 \\
Constant & .317 & 72.472 & .000 & 1.373 & & \\
\hline
\end{tabular}


odds ratios $[\operatorname{Exp}(B)]$, and $95 \%$ confidence intervals $(\mathrm{CI})$ for the adjusted odds ratio for the logistic regression with the criterion variable success.

To further examine the moderating relationship that age has on developmental status as it pertains to the success of a student in their first college-level mathematics course, a cross tabulation table was created for success by developmental status by age. This analysis shows that developmental students are successful $60.1 \%$ of the time and non-developmental students are successful $62.8 \%$ of the time, a difference of $2.7 \%$. The difference between developmental and non-developmental students is similar for traditionally aged students $(58.0 \%$ success for developmental students, $60.9 \%$ for nondevelopmental students) but is much larger for non-traditionally aged students ( $71.1 \%$ success for developmental students, $79.4 \%$ success for non-developmental students. The results of this cross tabulation are presented in Table 7.

\section{Research Question 2: Moderating Variables on Persistence}

To answer research question 2 , a binary logistic regression was performed with the criterion variable persistence and predictor variables gender, NTage, black, other ethnicity, developmental, and the interaction variables developmental* ${ }^{*}$ ender, developmental ${ }^{*}$ NTage, developmental ${ }^{*}$ black, and developmental*other. Examining the results of the Wald test on the interaction variables indicates that neither gender $(p=.634)$ nor ethnicity (black $p=.148$, other $p=.933$ ) moderates the effects of developmental mathematics status on the persistence of Virginia community college students who took a mathematics course in their first semester to enrollment in the college during the fall 2007 semester. The Wald test does indicate that age moderates the effects of 
Table 7

Crosstabs for Success by Developmental Status by Age

Developmental Status

\begin{tabular}{|c|c|c|c|c|c|}
\hline \multirow[t]{2}{*}{ Age } & \multirow[t]{2}{*}{ Success Category } & \multicolumn{2}{|c|}{ Developmental } & \multicolumn{2}{|c|}{ Non-Developmental } \\
\hline & & $\mathrm{N}$ & $\%$ & $\mathrm{~N}$ & $\%$ \\
\hline \multirow[t]{2}{*}{$17-22$} & Successful & 1965 & $(58.0)$ & 3924 & $(60.9)$ \\
\hline & Non-Successful & 1421 & $(42.0)$ & 2523 & $(39.1)$ \\
\hline \multirow[t]{2}{*}{23 and older } & Successful & 463 & $(71.1)$ & 610 & $(79.4)$ \\
\hline & Non-Successful & 188 & $(28.9)$ & 158 & $(20.6)$ \\
\hline \multirow[t]{2}{*}{ Total } & Successful & 2428 & $(60.1)$ & 4534 & $(62.8)$ \\
\hline & Non-Successful & 1609 & $(39.9 \%)$ & 2681 & $(37.2 \%)$ \\
\hline
\end{tabular}

developmental status on the success of Virginia community college students $(p=.015)$. The adjusted odds ratio indicates that a non-traditionally aged developmental mathematics student is $35.8 \%$ more likely to be successful than other groups. Table 8 presents the regression coefficients $(B)$, the Wald statistics, significance levels, adjusted odds ratios $[\operatorname{Exp}(B)]$, and $95 \%$ confidence intervals $(\mathrm{CI})$ for the adjusted odds ratio for the logistic regression with the criterion variable persistence.

To further examine the moderating relationship that age has on developmental status as it pertains to the persistence of a student to the fall 2007 semester, a cross 
Table 8

Logistic Regression Results for Persistence

$95 \% \mathrm{CI}$ for $\operatorname{Exp}(B)$

Variable

$B \quad$ Wald Significance

$\operatorname{Exp}(B) \quad$ Lower Upper

\begin{tabular}{lcccccc}
\hline Developmental & -.209 & 12.576 & .000 & .812 & .723 & .911 \\
Gender & .146 & 6.011 & .014 & 1.157 & 1.030 & 1.299 \\
NTage & -.538 & 24.162 & .000 & .584 & .471 & .724 \\
Black & -.419 & 21.105 & .000 & .658 & .550 & .787 \\
Other Ethnicity & .254 & 9.978 & .002 & 1.290 & 1.101 & 1.510 \\
Dev*Age & .306 & 5.942 & .015 & 1.358 & 1.062 & 1.738 \\
Dev*Gender & -.036 & .227 & .634 & .965 & .833 & 1.118 \\
Dev*Black & .152 & 2.097 & .148 & 1.164 & .948 & 1.431 \\
Dev*Other & -.009 & .007 & .933 & .991 & .806 & 1.219 \\
Constant & .500 & 131.041 & .000 & 1.648 & & \\
\hline
\end{tabular}

tabulation table was created for persistence by developmental status by age. This table shows that developmental students are persistent $56.9 \%$ of the time and nondevelopmental students are persistent $62.6 \%$ of the time, a difference of $5.7 \%$. The difference between developmental and non-developmental students is similar for traditionally aged students $(57.9 \%$ persistence for developmental students, $63.7 \%$ for 
non-developmental students) but is much larger for non-traditionally aged students (51.5\% persistence for developmental students, $49.7 \%$ for non-developmental students. Additionally, all developmental students and traditionally aged developmental students persist at lower rates than do non-developmental students, but non-traditionally aged developmental students persist at higher rates than non-traditionally aged nondevelopmental students. The results of this cross tabulation are presented in Table 9. Research Question 3: Extent Predictor Variables Account for Success

To answer research question 3 , a binary logistic regression was performed with

Table 9

Crosstabs for Persistence by Developmental Status by Age

Developmental Status

Age Success Category Developmental Non-Developmental

$17-22$

Persisted

$\mathrm{N} \% \quad \mathrm{~N} \%$

Did Not Persist

$3892(57.9 \%)$

$2957(63.7 \%)$

$2829 \quad(42.1 \%) \quad 1688 \quad(36.3 \%)$

23 and older Persisted

$666 \quad(51.5 \%)$

$183(49.7 \%)$

Did not Persist

$628(48.5 \%)$

$185(50.3 \%)$

Total

Persisted

$4558 \quad(56.9 \%)$

$3140 \quad(62.6 \%)$

Did not Persist

$3457 \quad(43.1 \%)$

$1873(37.4 \%)$ 
the criterion variable success and predictor variables gender, NTage, black, other ethnicity, developmental, and the interaction variables developmental*gender, developmental*NTage, developmental*black, and developmental*other. The constant only model for the success of a Virginia community college student indicates that $61.9 \%$ of students are successful in their first college-level mathematics course. This model provides a baseline comparison to a model which included the above listed predictor variables. An Omnibus Test of Model Coefficients was performed to determine if the model including the nine predictor variables provides an improved prediction of success. This test shows there is a significant $\left(\chi^{2}(9)=320.585, p<.001\right)$ improvement of $0.5 \%$ in the ability to predict success in the first college-level mathematics course taken.

To determine the level to which the model fits the data, the Nagelkerke pseudo $R$ Square statistic was used. The model which includes the predictor variables accounts for $3.8 \%$ of the variation in the success of Virginia community college students which can be explained by the nine predictor variables. A Hosmer and Lemeshow test determines if the predicted probabilities match the observed probabilities, meaning the set of predictor variables accurately predicts the criterion variable (Meyers et al., 2006). A Hosmer and Lemeshow test for this model was conducted and the Chi-square test was insignificant $\left(\chi^{2}(7)=5.174, p=.639\right)$ which indicates an acceptable match between the predicted and observed probabilities.

The purpose of research question 3 was to determine to what extent the nine predictor variables account for the success of Virginia community college students in their first college-level mathematics course. A Wald test was performed on the 
regression coefficients to determine if any of the predictor variables are statistically significant in predicting the success of students. The results of this Wald test are given in Table 6 and determined that developmental status, gender, age, and Black race and ethnicity are significant predictors of success. Additionally, age is a moderating factor on developmental status. More specifically non-developmental students, females, older students, and non-Black students succeed at higher rates in their first college-level mathematics course, and non-traditionally aged developmental students succeed at lower rates.

A more useful statistic to address the question of the effect a variable has on the criterion variable is the adjusted odds ratio. An adjusted odds ratio for each predictor variable in the logistic regression model for the success of Virginia community college students was computed and is provided in Table 6. The adjusted odds ratio indicates the contribution of the particular variable when the other variables are held constant (Meyers et al., 2006) and provides a comparison between the probability of the success in the first college-level mathematics course between two groups. The probability of experiencing success in the first college-level mathematics course for developmental students compared to non-developmental students is decreased $12.4 \%(95 \% \mathrm{CI}=0.01-23.2)$. The probability of experiencing success for females compared to males is increased $45.8 \%(C I=32.3-60.7)$. The probability of experiencing success for non-traditionally aged students compared to traditionally aged college students is increased by $159 \%(\mathrm{CI}=$ $116-212)$. The probability of experiencing success for Black students compared to non- 
Black students is decreased by $39 \%(\mathrm{CI}=29.0-47.6)$. The probability of experiencing success for non-traditionally aged developmental students compared to other groups is decreased by $29.9 \%(\mathrm{CI}=8.9-46.1)$.

The results of the logistic regression provided an equation to calculate the natural logarithm of the odds a student has success in their first college-level mathematics course (Meyers et al., 2006). Transforming the log odds into a predicted probability can be done by taking the antilog of the regression equation (Meyers et al.). The predicted probabilities for the success of a student in their first college-level mathematics course for each possible combination of developmental status, age, race and ethnicity, and gender are presented in Appendix A.

\section{Research Question 4: Extent Predictor Variables Account for Persistence}

To answer research question 4, a binary logistic regression was performed with the criterion variable persistence and predictor variables gender, NTage, black, other ethnicity, developmental, and the interaction variables developmental*gender, developmental*NTage, developmental*black, and developmental*other. The constant only model for fall-to-fall persistence of a Virginia community college student who took a mathematics course in their first semester indicates that $59.1 \%$ of students persisted to a second year of college. This model provides a baseline comparison to a model which included the above listed nine predictor variables. An Omnibus Test of Model Coefficients was performed to determine if the model including the nine predictor variables provides an improved prediction of success. This test shows there is a 
significant $\left(\chi^{2}(9)=185.615, p<.001\right)$ improvement of $0.1 \%$ in the ability to predict the fallto-fall persistence of Virginia community college students by using the model including the nine predictor variables.

To determine the level to which the model fits the data, the Nagelkerke pseudo $R$ Square statistic was used. The model which includes the nine predictor variables accounts for $1.9 \%$ of the variation of the fall-to-fall persistence of Virginia community college students which can be explained by the model. A Hosmer and Lemeshow test was performed to determine if the predicted probabilities match the observed probabilities. This Chi-square test was insignificant $\left(\chi^{2}(6)=2.527, p=.865\right)$ which indicates an acceptable match between the predicted and observed probabilities.

The purpose of research question 4 was to determine to what extent the nine predictor variables account for the fall-to-fall persistence of Virginia community college students. A Wald test was performed on the regression coefficients to determine if any of the predictor variables are statistically significant in predicting the fall-to-fall persistence of students. The results of this Wald test are given in Table 8 and determined that developmental status, gender, age, Black race and ethnicity, and other race and ethnicity are significant predictors of success. Additionally, age is a moderating factor on developmental status. More specifically non-developmental students, females, traditionally aged students, non-Black students, and other racial and ethnic groups persist at greater rates to a second year of college. This greater persistence is true for nontraditionally aged developmental students. 
A more useful statistic to address the question of the effect a variable has on the criterion variable is the adjusted odds ratio. An adjusted odds ratio for each predictor variable in the logistic regression model for the fall-to-fall persistence of Virginia community college students was computed and provided in Table 7. The adjusted odds ratio indicates the contribution of the particular variable when the other variables are held constant (Meyers et al., 2006) and provides a comparison between the probability of the fall-to-fall persistence between two groups. The probability of experiencing persistence to a second year of college for developmental students compared to non-developmental students is decreased by $18.8 \%(95 \% \mathrm{CI}=9.0-27.7)$. The probability of experiencing persistence for females compared to males is increased by $15.7 \%(\mathrm{CI}=3.0-29.9)$. The probability of experiencing persistence for non-traditionally aged students compared to traditionally aged college students is decreased by $41.6 \%(\mathrm{CI}=27.6-52.9)$. The probability of experiencing persistence for Black students compared to non-Black students is decreased by $34.2 \%(\mathrm{CI}=21.3-45.0)$. The probability of experiencing persistence for students of other racial and ethnic groups compared to students not in those groups is increased by $29 \%(\mathrm{CI}=10.1-51.0)$. The probability of experiencing persistence for non-traditionally aged developmental students compared to other groups is increased by $35.8 \%(\mathrm{CI}=6.2-73.8)$.

The results of the logistic regression provide an equation to calculate the natural logarithm of the odds a student persists to a second year of college (Meyers et al., 2006). Transforming the log odds into a predicted probability can be done by taking the antilog of the regression equation (Meyers et al.). The predicted probabilities for the persistence 
of a student to a second year of college for each possible combination of developmental status, age, race and ethnicity, and gender are presented in Appendix B.

\section{Summary}

This chapter has introduced the findings of the study. Descriptive statistics for the sample were presented along with the results of the predictive models used to answer the research questions. The findings presented in this chapter identified variables which were significant additions to the predictive models and reported adjusted odds ratios of the predictor variables which represent the contribution of the particular variable to the criterion variable. The next chapter will provide a summary of these results and will discuss the implications of these findings. 


\section{CHAPTER V}

\section{SUMMARY AND DISCUSSION}

The final chapter of this study will review the research problem and the methodology used in the study. The major sections of this chapter will briefly review the background of the study, the problem which was examined, the questions which guided the study, the significance of the study, a review of the methodology, and the findings. Finally, these findings will be discussed including implications of the findings and suggestions for implementing the findings in practice. Finally, suggestions for future research will be given based on the results of this study.

\section{Background of the Problem}

In 2008 the Virginia Community College System (VCCS) created the Developmental Education Task Force to begin focusing on the state of developmental education in its 23 member community colleges. This process has culminated with the implementation of a redesigned mathematics curriculum in the VCCS beginning with the 2012 spring semester. As part of this redesign effort, the VCCS included a recommendation calling for a system-wide annual report on developmental education to track progress towards meeting system-wide goals (VCCS, 2009).

The need for improving developmental education has been well documented in the literature. Many states and institutions have begun to closely examine outcomes of developmental education and have redesigned programs to improve these outcomes (FLDoE, 2011a; Gonzalez, 2011; Mireless, 2010; VCCS, 2011) as post-secondary education is critical for success at both the individual and global level (McIntosh \& 
Rouse, 2009; USDoE, 2006). Many students, particularly those in community colleges, enter higher education unprepared to meet the demands of college-level academic work (Cohen \& Brawer, 2008) and developmental education serves to aid these students become ready to succeed in higher education.

Two common areas in which higher education students are measured are their performance in courses and their persistence to a degree or certificate. The level of success in college-level courses a student earns is particularly applicable to developmental students as the goal of developmental education is to prepare students for success in college-level courses. The results of past comparisons of success for students requiring developmental mathematics education and those not requiring developmental coursework has been mixed with some studies (Bahr, 2008; Calcagno, 2007) finding similar levels of success, whereas others (Biegel, 2009; Parmer \& Cutler, 2007) have found developmental students performed worse in college-level courses. Persistence of a student is important to examine as earning a terminal degree or certificate generally requires more than one year of higher education course. Examining the persistence of students to a second year of higher education, often referred to fall-to-fall persistence, is a common and appropriate length of time to use as most students who drop out of higher education do so in their first year (Tinto, 1993). Past literature has provided evidence to support that the persistence of students is positively affected by developmental courses (Calcagno, 2007; Fike \& Fike, 2008).

Demographic characteristics of students enrolled in community colleges are diverse. Approximately one third of community college students are non-White, $60 \%$ are 
female, and $50 \%$ are of non-traditional age (Cohen \& Brawer, 2008). This diversity provides researchers with the opportunity to examine the outcomes based on demographic groups to determine if particular demographic groups have greater needs. This can be particularly important with developmental students. Understanding the characteristics of students in developmental education can better direct resources to groups which are over-represented. Past literature has generally identified that nonWhite students, particularly Black students, have lower levels of success and persistence (Bailey et al., 2010; Fike \& Fike, 2007; Roksa et al., 2009). Male students have lower levels of success than do their female counterparts (Cho, 2011; Roksa et al.). The literature which examines persistence defined as continued enrollment is limited, although women graduate at higher rates than do males (Bailey et al., 2005; Cooper, 2009). Most literature has reported that older students find more success than younger (Cho; Fike \& Fike) but the literature is limited and inconclusive on differences in persistence between students of different ages.

The Developmental Education Annual Report (VCCS, 2011) was the first compilation of data resulting from the recommendation for annual reports of data by the Developmental Education Task Force. The Developmental Education Annual Report described the 2006 cohort of first-time-in-college students from all 23 Virginia community colleges and provided descriptive statistics about this cohort on measures designed to address the Task Force's recommendations. Understanding which developmental students are struggling to meet standards will help the Virginia Community College System better direct funds and other resources to aid those students. 
This study extended the descriptive statistics presented on the 2006 cohort from the Annual Report by statistically examining the differences between developmental and non-developmental students and their success in the first college level mathematics course taken and persistence of students into a second year of college.

\section{Purpose Statement and Research Questions}

The purpose of this quantitative study was to examine the effect of age, gender, and race and ethnicity together with developmental mathematics status on student's persistence to a second year and academic performance in the student's first college level mathematics course in Virginia community colleges. This study utilized the data reported by the Virginia Community College System in: "Developmental Education Annual Report: Tracking the Fall 2006 Cohort and Five-Year Historical Trends" (VCCS, 2011).

This study was guided by the following research questions:

1. Are there moderating variables on developmental mathematics status in determining the success of Virginia community college students in their first college-level mathematics course?

a. Does student race and ethnicity moderate the effects of developmental mathematical status on the success of Virginia community college students in their first college-level course?

b. Does student gender moderate the effects of developmental mathematical status on the success of Virginia community college students in their first college-level course? 
c. Does student age moderate the effects of developmental mathematical status on the success of Virginia community college students in their first college-level course?

2. Are there moderating variables on developmental mathematics status in determining the fall-to-fall persistence of Virginia community college students?

a. Does student race and ethnicity moderate the effects of developmental mathematical status on the fall-to-fall persistence of Virginia community college students?

b. Does student gender moderate the effects of developmental mathematical status on the fall-to-fall persistence of Virginia community college students?

c. Does student age moderate the effects of developmental mathematical status on the fall-to-fall persistence of Virginia community college students?

3. To what extent do developmental status, gender, age, race and ethnicity, and interactions between developmental status and age, developmental status and gender, and developmental status and race and ethnicity account for success of Virginia community college student in their first college-level mathematics course?

4. To what extent do developmental status, gender, age, race and ethnicity, and the interaction between developmental status and age, developmental status and 
gender, and developmental status and race and ethnicity account for the fall-to-fall persistence of Virginia community college students?

\section{Significance}

Research on the effectiveness of developmental education is limited and produces mixed results despite the fact developmental education is a large part of community college curriculums (McIntosh \& Rouse, 2009). This statement is particularly applicable to research on the persistence of community college students. Research on large, statewide, samples of community college students has generally found similar levels of success between developmental and non-developmental students, and similar or higher levels of persistence from developmental students. This study adds to the knowledge base of such samples. Additionally, the VCCS has just implemented a redesign of their developmental mathematics program in part to improve the success of developmental students. As part of the tracking of the progress of developmental students the VCCS will publish an annual developmental education report. Comparing student outcomes under the former developmental design with outcomes from the redesign will help determine if the redesign has improved success. The first such annual report provided descriptive statistics for the success of developmental students. This study expanded the knowledge of the success of developmental students under the former system by not only examining the data using statistical models but also providing a more detailed breakdown of student outcomes by using common demographic groups.

\section{Methodology}

Ex post facto data were gathered from the VCCS for the cohort of First-Time-in- 
College students from all 23 Virginia community colleges. These data were used to create the dichotomous variables Non Traditional Age, Female, Black, Other Ethnicity, Developmental Status, Success, and Persistence. These variables were coded with a 1 to represent a student had the described attribute and were coded with a 0 if the student did not possess the described attribute. Additionally, interaction variables were created by taking the product of developmental status and age, developmental status and gender, developmental status and black, and developmental status and other ethnicity to determine if there were moderating variables on developmental status.

Descriptive statistics were then provided to describe the sample used for this study. Logistic regressions were used to answer the research questions. Two regression models were created, one with the criterion variable success and the other with the criterion variable persistence. Each model used nine predictor variables: age, gender, Black, Other Ethnicity, Developmental Status, and the four interaction variables. Significance of the model and variables were determined at the 0.05 level and adjusted odds ratios were used to determine the extent each variable contributed to the success and persistence of Virginia community college students.

\section{Results}

The sample of students from the 23 Virginia community colleges who were FirstTime-in-College students during the 2006 fall semester who met the criteria for the study numbered 17,335 . These students were predominately female (53.6\%), traditional college age (85.2\%), White (62.9\%) and were identified as developmental 
students by virtue of their first mathematics course being a developmental one $(58.4 \%)$. Descriptive statistics on the criterion variables show $40.2 \%$ of the students in the sample were successful in their first college-level mathematics course, $24.7 \%$ of the students were not successful, and $35.1 \%$ of the students never attempted a college-level mathematics course. Statistics for the criterion variable persistence show $24.8 \%$ of students did not take a mathematics course during their first semester, $44.4 \%$ of the students took a mathematics course in their first semester and persisted to the fall 2007 semester, and $30.7 \%$ of the students took a mathematics course in their first semester and did not persist to the fall 2007 semester.

The regression models show age moderates the effects of developmental status on both the success and persistence of students, namely non-traditionally aged students succeed at lower rates and persist at higher rates than do other students. The models also show non-developmental students, female students, non-traditionally aged students, and non-Black students all have higher levels of success in their first college-level mathematics course. Additionally, non-developmental students, female students, traditionally aged students, and non-Black students all have significantly higher levels of persistence to the fall 2007 semester than do their respective counterparts.

\section{Discussion}

The following sections will discuss the findings for each research question from this study. The discussion for each question will include how the findings compare to 
previous research, implications for practitioners, and researcher insights. The discussion will conclude with an overall summary section and recommendations for future research.

\section{Research question 1: Moderating variables on success}

Most previous studies, particularly those with large samples, have reported that developmental students succeed at similar rates to non-developmental students (Bahr, 2008; Calcagno, 2007; Roksa et al., 2009). Researchers who have reported different results have generally examined small or unique samples, such as a single institution (Byrd, 2004; Germanna Community College, 2002; Gonzales, 2007; Parmer \& Cutler, 2007) or urban colleges (Dubray, 2005). Therefore, for the general population of developmental students who complete their developmental coursework the level of success is similar to that of non-developmental students.

There is a differentiation in the success of community college students based on demographic characteristics of those students. Specifically, most research has found that non-White students (California Community Colleges, 2011a; Fike \& Fike, 2007), and particularly Black students (Bailey et al., 2010; Roksa et al., 2009; Sullivan, 2010), have lower rates of success than do White students; female students outperform their male counterparts (Alvarez, 2008; Roksa et al.); and older students succeed at higher rates than do traditionally aged students (Alvarez; California Community Colleges, Kolajo, 2004). The demographic categories, gender, age, and race and ethnicity, are important to study in the community college as the community college student population has high numbers of non-majority ethnicities, females, and older students (Cohen \& Brawer, 2008). 
Despite the growing knowledge on the success of students from different demographic groups, and the current knowledge of the success of developmental students, there has been little empirical investigation of the effect of developmental coursework on members of different demographic groups. Therefore, the first research question of the current study attempted to determine if there were moderating factors in determining the success of developmental students.

This study found that neither gender nor ethnicity moderated the effects of developmental status on the success of students in their first college-level mathematics course. In other words, the success of developmental students in their first college-level mathematics course did not depend on the race and ethnicity or gender of the student. This study did find age did moderate the effects of developmental status on the success of Virginia community college students in their first college-level mathematics course. To further examine this moderation effect a frequency table of success by developmental status by age was created. As indicated in Table 7,60\% of developmental students were successful in their first college-level mathematics course, $2.7 \%$ less than nondevelopmental students. Students of traditional age had a similar spread in success rates: the percentage of traditional aged developmental students who succeeded was $2.9 \%$ less than traditional aged non-developmental students. However, the difference in success rates for non-traditional aged developmental students was $8.3 \%$ less than non-traditional aged non-developmental students. Therefore, the effects of developmental coursework 
were stronger for traditional aged students than they were for non-traditional age students when measuring the success of students in their first college-level mathematics course.

\section{Researcher insights}

The majority of community college students require developmental coursework to raise their level of academic work to that expected at the college level. Bailey (2009) reported that $60 \%$ of community college students require developmental coursework, a figure supported by the sample used for the current study. One major mission of community colleges is to help underprepared students be successful in higher education (VCCS, 2009). It is important this assistance to underprepared students help all students equally. Should there be a moderating effect of developmental status on the success of students in college-level courses it would show a flaw in the developmental education program in Virginia.

The findings from this study show the developmental program in Virginia helps the majority of demographic groups equally. The only exception was non-traditional aged students. The success rate for developmental students from this demographic group was not as close to non-developmental students as it was for traditional aged students. Several researchers (Kozerackie, 2002; Tinto, 1993) have commented that the farther away from previous academic work a student is the more difficult it is for those students to be successful which is supported by the findings from the current study. As developmental coursework does not help non-traditional aged students succeed as well as other demographic groups, community colleges can better aid these students by providing extra help in study skills and methods to improve math learning. However, the need to 
address weakness in developmental coursework for non-traditional aged students is most likely not seen as critical in community colleges for even though non-traditional aged developmental students do not reach the comparative success to their non-developmental peers, their actual level of success, $71 \%$ in the current study, is much higher than any other group had in their college-level mathematics courses.

\section{Implications and recommendations for practitioners}

Success in college-level mathematics courses for students beginning in developmental courses does not depend on the gender or race and ethnicity of the student. However, the results of developmental education are lower for non-traditional aged students. Developmental education is not as effective for that demographic group. Perhaps, the reason for this inequity is that younger students are more familiar with the requirements of academia, a position supported by Biegel (2009) who found students enrolling in community college more than two years after graduating from high school were half as likely to be successful in college-level courses.

Therefore, community colleges should consider adding a student development course (SDV) for non-traditionally aged students. Similar to the SDV course currently required for all Virginia community college students, the SDV course focused on the non-traditional aged student could include time-management ideas for working adults, note-taking skills, organizational skills, and study skills. An additional resource which could help the non-traditional aged student is to develop or provide links to online, asynchronous sites to where students could receive help. The asynchronous nature of 
such a site could offset time management problems which could be greater for the nontraditional student.

In addition to providing additional resources and information to the nontraditional aged student, community colleges should consider additional training to their instructors on the different concerns and issues of all students, particularly those differentiated by age. The more an instructor can individualize instructions and interactions to students, both inside and outside of the classroom, the more effective that instructor can be in facilitating learning by the student.

\section{Research question 2: Moderating variables on persistence}

The persistence of students is very difficult to attribute to any one factor, as students, particularly community college students, leave higher education for many different reasons. Most of the reasons students leave are not in the control of the institution (Braxton et al., 2004; Cohen \& Brawer, 2008). Bailey et al. (2010) further described the difficulty in accurately determining the persistence of students by explaining initial enrollment in college could be seen as an experiment for students to determine their ability to succeed in higher education. Research has shown that approximately half of community college students do not persist to a second year of college (Braxton et al.; Fike \& Fike, 2008). Among the reasons which are commonly cited for contributing to the non-persistence of students are gender, ethnicity, and delayed entry to college (Attewell et al., 2011). Therefore, these are important demographic characteristics to examine in conjunction with the persistence of students. 
Almost every study has reported the persistence of developmental students to be the same or greater than that of non-developmental students (Bahr, 2007; Fike \& Fike, 2008; Roksa et al., 2009) with the majority of those studies showing greater persistence for developmental students. Particularly, Calcagno (2007) found the relationship of developmental coursework to increased persistence to be causal. Understanding differences in persistence among demographic groups within developmental education is important to determine if the demographics of developmental students affects persistence.

The current study determined that neither gender nor ethnicity was a moderating factor of developmental status on the persistence of students. This result indicates that developmental education does not adversely affect these demographic groups. This study did find age does moderate the effects of developmental status on the fall-to-fall persistence of Virginia community college students. To further examine this moderation effect, a frequency table of success by developmental status by age was created (see Table 9). This table shows that $56.9 \%$ of developmental students persist to a second year, a rate which is $5.7 \%$ less than non-developmental students. Students of traditional age have a similar spread in success rates: the percentage of traditional aged developmental students who persist is $5.8 \%$ less than non-developmental students. However, the difference in persistence rates for non-traditional developmental students is $1.8 \%$ greater than non-developmental students.

Therefore, developmental coursework not only affects the persistence of students differently based upon the age of the student, but this effect occurs in opposite directions. The persistence of traditional aged developmental students is negatively impacted by a 
similar margin as developmental students in general. The persistence of non-traditional aged developmental students is greater than non-traditional, non-developmental students.

\section{Researcher insights}

As previously discussed, the causes for non-persistence of a student are very difficult to attribute to any one factor. Most previous research has found that developmental students persist at higher rates than do non-developmental students but has not addressed factors which may differentiate the persistence of developmental students. Only one previous study reported on a moderating effect of persistence on developmental status. Jefferson (2010) found that the motivation of the student was more important to their persistence than were faculty interactions. An increased motivational factor is one possible cause for the moderating effect age had on developmental status in the current study. In other words, non-traditional aged students who require developmental mathematics courses may be more willing to persist with their education to meet their goals than a traditional aged student who is required to take developmental coursework.

\section{Implications and recommendations for practitioners}

Age was found to have a moderating effect of developmental status on the persistence of students. There are several implications from this result. First, community college instructors should consider paying particular attention to the non-traditional aged students in developmental courses as they may have a greater motivation to succeed and could thus be more receptive to instruction. Second, traditional aged developmental students persist at lower rates. Institutions should consider designing their developmental 
programs or create new programs to allow students the opportunity to progress quickly through their developmental coursework so younger students may reach college-level courses more quickly to improve motivation. The Virginia Community College System has made decreasing the time to complete developmental coursework one of its three goals for developmental education. This goal was stated by the Developmental Education Task Force in The Turning Point (VCCS, 2011): to design developmental education so students can complete developmental requirements in one academic year.

\section{Research question 3: Extent predictor variables account for success}

The purpose for this research question was to examine the extent to which developmental status, age, gender, and race and ethnicity accounted for the success of students in their first college-level mathematics course. The result of the logistic regression model created to answer this question show the model significantly improves the ability to predict success. However, this improvement is only $0.5 \%$ which suggests the practical significance of this model is low. An additionally statistic which supports the low practicality of the significance of the improvement, the Nagelkerke pseudo $R$ Square, shows $3.8 \%$ of the variation in success rates is accounted for by the predictor variables in the model. Another way to consider this statistic is over $96 \%$ of the variation is explained by factors other than the developmental status, age, race and ethnicity, and gender of the student. The low percentage of variation in the success rates of community college students explained by this model supports the findings of Attewell et al. (2006) who found preexisting skill differences, and not demographic information, accounted for most of the gap in graduation rates of community college students. 
The following sections will provide discussion on each of the four predictor variables individually.

\section{Developmental status}

The VCCS (2011) reported a slight difference in the success rates of students by using descriptive statistics to report $73 \%$ of non-developmental students and $67 \%$ of developmental students succeeded in their first college-level mathematics course. Roksa et al. (2009) examined the 2004 cohort of First-Time-in-College students in Virginia community colleges and reported no difference in the success rates of developmental and non-developmental students. The results from these two studies of inclusive state-wide samples of first-time-in-college students in Virginia community colleges match the majority of research on the success of developmental students in college-level courses, particularly those of large and diverse samples.

The descriptive statistics from the current study did not match the statistics provided in the VCCS report on the same sample. The current study found that $60 \%$ of developmental students and $62 \%$ of non-developmental students were successful in their first college-level mathematics course. This compares to the VCCS report of $67 \%$ developmental and $73 \%$ non-developmental. One possible reason for the different findings in the two reports is the current study examined data for a five year period and the VCCS report used a two year time period. Therefore, the difference between the two figures could represent students who delayed their mathematics coursework, or took an extended time to complete their developmental coursework. If this were a contributing factor for the difference in the two reports it would support the finding by Biegel (2009) 
who reported students who enroll in community college more than two years after graduating from high school were half as likely to be successful in college-level courses. The difference in success rates between a two-year time period and five-year time period could arise from a similar delaying factor.

The findings on developmental status from this study show developmental students have significantly lower success in their first college-level mathematics course than non-developmental students. However, the effect size from developmental status is not large. Developmental students have a success rate which is $12.4 \%$ lower than nondevelopmental students. Additionally, the significance level, while significant, is barely so at $p=.048$. This finding is different from the majority of previous studies which found no difference in the success rates of developmental and non-developmental students. However, even though the current study found a significant difference, the size of the difference was small and developmental status did not have a large effect on the success of a student.

\section{Age}

The VCCS (2011) did not provide statistics on the success of students in their first college-level course based upon the age of the student. They did report that $79 \%$ of the sample was traditionally aged students and the current study found that $85 \%$ of the sample is traditionally aged. The difference in these rates could derive from the elimination of students who never took a mathematics course or were younger than 17 which is approximately $25 \%$ of the original sample. These groups of students were included in the VCCS sample. Roksa et al. (2009) examined the 2004 cohort of First- 
Time-in-College students in Virginia community colleges and reported older students had more success in college-level courses. This finding mirrored the findings of the majority of past studies in that older students are generally more successful in their coursework than younger students.

The current study found that age is a significant predictor of success in the first college-level mathematics course; specifically non-traditionally aged students succeed at higher rates than traditionally aged students. The effect age had on the success of students in their first college-level mathematics course in the current study is larger than any other variable in the study. A non-traditional aged student is approximately 2.6 times as likely to succeed in their first college-level course as is a traditional aged student. This result supports previous research, particularly the comments of Byrd and Macdonald (2005) who postulated that the skills older students have obtained from their life experiences are a large contributor to their success.

\section{Gender}

The VCCS (2011) did not provide statistics on the success of students in their first college-level course based upon the gender of the student. They did report that $54 \%$ of the sample was female. This statistic is also the percentage of females reported in the current study. Roksa et al. (2009) examined the 2004 cohort of First-Time-in-College students from Virginia community colleges and reported female students had more success in college-level courses. This result supported previous studies which almost universally have found female students are more successful in their coursework than male students. 
The finding of greater success for female students was also confirmed in the current study. Particularly, female students have approximately a 50\% greater chance of being successful in their first college-level mathematics course than do males.

\section{Race and ethnicity}

The VCCS (2011) did not provide statistics on the success of students in their first college-level mathematics course based on the race and ethnicity of the student. They did report that $62 \%$ of their sample was White and $21 \%$ was Black which matches the statistics from the current study. Roksa et al. (2009) examined the 2004 cohort of First-Time-in-College students in Virginia community colleges and found Black students had lower levels and Asian students had higher levels of success in college-level courses.

Prior research generally reports Black students have lower levels of success than other racial and ethnic groups (Bailey et al., 2010; California Community Colleges, 2011 a; Fike \& Fike, 2007; Roksa et al., 2009). However, several studies have shown no differences in the levels of success of White and non-White students. Perhaps one reason for the conflicting findings in past research is Asian students have higher levels of success (Roksa et al.) and the effects of Black and Asian students offset each other. The findings of the current study of Black students being $39 \%$ less likely to succeed in their first college-level mathematics course supports previous research which found Black students have significantly lower chances of succeeding in college-level courses.

\section{Researcher insights}

The current study has confirmed many of the general findings from past research on the success of community college students. Past studies have shown developmental 
students succeed at similar rates than do non-developmental students, older students succeed more than younger students, female students perform better than male students, and Black students perform worse than non-Black students. The results from the current study confirm each of these previous findings. Even though the current study did find a significant difference in success rates for developmental and non-developmental students, the practical difference in these two groups is low which indicates a similar success rate for the two groups.

The current study has also lent support to several other important concepts which have been postulated by previous researchers. Several studies (Attewell et al., 2011; Bettinger \& Long, 2005; Linfante, 2002) have examined graduation rates of students by controlling for demographic and pre-existing factors and found that developmental education does not negatively affect success. The current study finds only $3.8 \%$ of the variation of success is due to developmental status, age, race and ethnicity, and gender of the student. Therefore, there must be other factors which more completely explain the variation in success rates. Bettinger and Long (2009) emphasized the inappropriateness of comparing developmental and non-developmental students as they reported there are inherent differences between these groups of students. These differences between developmental and non-developmental students may derive from inherent differences in the academic abilities, motivations, secondary school education, financial resources, and other factors which are not controlled by higher education institutions. Understanding factors leading to differences in success rates which can be controlled either directly by higher education institutions or by increased knowledge of those differences is important, 
but equally important may be the realization by higher education institutions and interested parties that many factors which create differences in the success rates of students may not be changeable by the institution.

A major contributing factor to traditionally aged students and Black students having lower rates of success is a poor preparation for higher education from the secondary school systems in the United States (Alliance for Excellent Education, 2011; Bailey et al., 2010; Hawley \& Harris, 2005; Martino \& Wilson, 2009; USDoE, 2006) and the lack of availability to quality education for students in poor regions of the country (Alliance for Excellent Education).

An additional contributing factor for low success rates identified in past research has been the detrimental effect of delaying higher education. Several researchers (Calcagno, 2007; Johnson \& Kuennen, 2004) have argued that the more a student delays their developmental education the less likely they are to successfully complete their course. The current study supports this contention as age was found to have a moderating effect on developmental status on the success of students. Specifically, this moderating effect indicates that non-traditionally aged students are not assisted as much by developmental education as are traditionally aged students.

One important note to make about the success developmental students find in their college-level mathematics courses is the large number of developmental students who never attempt a college-level mathematics course. Whereas most studies, including the current one, have found little or no difference in the success rates of developmental and non-developmental students, these studies examine only those students who have 
enrolled in a college-level mathematics course. By using this sample of students to compare success rates of developmental and non-developmental students, the number of developmental students who never take a college-level course is hidden. Previous research has indicated that $65 \%$ to $75 \%$ of students do not complete their developmental coursework (Bailey et al., 2010) and fewer than $20 \%$ of developmental students ultimate pass a college-level course (Bailey et al.; VCCS, 2009). The sample for the current study shows slightly more positive statistics as $40 \%$ of developmental students attempted a college-level mathematics course and $24 \%$ of developmental students ultimately passed a college-level mathematics course. In this regard, the current study does confirm past research on the proportion of developmental students who never reach a college-level mathematics course. Any research which discusses the success of developmental students should be clear as to the samples being used for comparison. Therefore, the current study confirms that "when remediation works, it works extremely well" (Bahr, 2008, p. 444). But also confirms the majority of developmental mathematics students never attempt a college-level mathematics course. The issue of the large number of developmental students who never reach college-level mathematics courses is separate from the success developmental students find once they reach college-level courses.

\section{Implications and recommendations for practitioners}

A major implication taken from this study for practitioners is few of the differences in success rates of students in college-level mathematics courses can be attributed to the developmental status of the student. Practitioners should not be concerned with the ability of developmental students to be successful in college-level 
courses. Developmental students succeed in college-level courses at similar rates than non-developmental students.

There are differences in success rates based on demographic characteristics of students. Particularly, traditionally aged students, male students, and Black students have lower levels of success in college-level mathematics courses. Of these groups, Black students and males students had the lowest success rate in college-level mathematics courses. Practitioners should seek out classroom practices which aid these groups of students. James (2007) provided suggestions to instructors for increasing the learning of male students. Among these suggestions were to move around the classroom, provide additional pause time after asking a question, allow men to work the problem in one-onone work, and to talk to the class during lectures and not to the board. Additionally, instructors should consider creating classroom assignments and examples which Black students and male students can better relate. If the relationship of classroom mathematical skills can be better demonstrated by applying those skills to experiences from outside the classroom, the retention of the mathematics skills should be strengthened.

To address the needs of traditionally aged students, community colleges in Virginia should consider making a greater emphasis on study skills courses to aid students in their transition to community college. Particular care should be taken to emphasize the differences between expectations of students from faculty and the differences in the learning process between high school courses and college courses. 
In Virginia, achieving the first of three goals recommended by the Developmental Education Task Force (VCCS, 2009) will provide the greatest increase in student success. This goal is to reduce the need for developmental education. As the current study shows, more than $96 \%$ of the variation in the success rates of students in their first college-level mathematics course comes from variables other than developmental status, age, race and ethnicity, or gender. Previous studies have indicated a significant portion of this variation may be explained by individual student factors and factors relating to the secondary education of these students. Community colleges, county and city school boards, and communities should consider working together to identify ways to better educate instructors and students in secondary schools as to the level of knowledge expected for success in higher education.

\section{Research Question 4: Extent Predictor Variables Account for Persistence}

The purpose for this research question was to examine the extent to which developmental status, age, gender, and race and ethnicity accounted for the fall-to-fall persistence of students. The logistic regression used to answer this question found the model significantly improved the ability to predict persistence. However, the improvement in the ability to predict persistence is only $0.1 \%$ which suggests the practical significance of this model is almost non-existent. Additionally, the Nagelkerke pseudo R Square shows that $1.9 \%$ of the variation in persistence rates was accounted for by the predictor variables. This means over $98 \%$ of the variation is explained by other factors. The small amount of variation in the persistence rates of this sample for the predictor variables supports previous literature which has emphasized the difficulty in 
determining the causes of persistence (Attewell et al., 2011) and the supposition that often the reasons students do not persist are beyond the control of the institution (Cohen \& Brawer, 2008).

The following sections will provide discussion on each of the four predictor variables for the fall-to-fall persistence of students individually.

\section{Developmental Status}

The VCCS (2011) reported developmental students persisted at higher rates than did non-developmental students $(55 \%$ to $52 \%)$ by using descriptive statistics. It was not reported whether this difference was statistically significant. Roksa et al. (2009) examined the 2004 cohort of First-Time-in-College students in Virginia community colleges and reported regardless of developmental status there was no difference in the number of semesters a student was enrolled. The majority of previous research has indicated the persistence of developmental students is higher than that of nondevelopmental students.

The current study presents contradictory findings not only in comparison to the VCCS study (VCCS, 2011) which used the same sample as the current study and Roska et al. (2009) but also to prior research. The current study found that developmental students persist at significantly lower rates than non-developmental students. The effect size of this relationship is relatively low as developmental students were $18.8 \%$ less likely to persist than non-developmental students. Prior research which has attributed a cause to the increased persistence of developmental students (Karp et al., 2010; Tinto, 1997; Waycaster, 2001) often refer to Tinto's Model of Student Integration (Tinto, 1993) 
as an explanation for the increased persistence of developmental students. Particularly, Waycaster posited that smaller developmental class sizes and advisement led to greater persistence of developmental students, and Karp et al. found student-centered pedagogies appeared to help students create social networks.

One possible cause for the contrary findings of the current study is the sample used to determine persistence. This study used a sample group of students who had taken a mathematics course in their first semester to determine inclusion in the developmental and non-developmental groups. The eliminating of students who did not take a mathematics course may have disproportionately eliminated developmental and nondevelopmental students. For example, students who were enrolled in a one or two semester certificate program which did not require mathematics would be excluded from the sample in the current study. These students would be classified in other studies as non-developmental students, and would be recorded as not persisting to a second year thus reducing the persistence rate for non-developmental students.

An additional possibility for the contradictory findings in this study as compared to previous literature is the difficulty in attributing persistence to any one factor (Attewell et al., 2006; Braxton et al, 2004). Particularly, Attewell et al. and Braxton et al. both reported that most of the gap in graduation rates of college students had little to do with developmental courses and instead reflected pre-existing skill differences in the students. Braxton et al. further described the departure of college students as an ill-structured problem which requires a number of possible solutions. The results of the current study 
may have been affected by variables which were not examined in this ex post facto methodology.

A third possibility for the contradictory findings may be an increased number of developmental students in Virginia who take their developmental coursework through distance education or in a computer based format. All three of the largest community colleges in Virginia, accounting for over half the student population, currently offer significant portions of their developmental courses through these formats. Perhaps it is the delivery method which has affected lower persistence of developmental students.

\section{Age}

Prior research is limited and has presented conflicting findings when persistence is examined using the framework of age. However, the most recent literature has generally concluded age negatively impacts persistence (Akst, 2007; Fike \& Fike, 2008). The current study supports this assertion as age was found to be a significant predictor of persistence. Namely, non-traditionally aged students are $41.9 \%$ less likely to persist as are traditionally aged students. This result is most clearly shown by examining descriptive statistics which show $60 \%$ of traditionally aged students persisted to a second year and $51 \%$ of non-traditionally aged student persisted.

There could be several possibilities for the lower persistence of non-traditionally aged students. Ayers (2002) reported a major theme of the mission of community colleges is workforce and economic developmental. Adult students often enter community colleges for specific job training, certificate programs, or personal interest (Cohen \& Brawer, 2008) which may take less than a year to complete. Bailey et al. 
(2005) suggested students enroll in community college to determine their aptitude for higher education and a lack of persistence may be due to their personal determination that the barriers are too high to continue. This examination of the aptitude and barriers of higher education may be particularly true for non-traditionally aged developmental students.

\section{Gender}

Prior research has indicated that women persist to graduation at higher rates than do men (Bailey et al., 2005). However, prior literature which has attempted to examine the persistence of students defined by continued enrollment based on gender is limited. The current literature has generally reported that gender is not a significant predictor of persistence (Moore, 2006; Stewart, 2010; Pelkey, 2011).

The current study found that gender is a significant predictor of persistence. However, the effect size of this difference is small. Females are $15.7 \%$ more likely to persist to a second year of school than are male students. This low effect size is shown by the descriptive statistics which show $59.9 \%$ of females persist and $58.2 \%$ of males persist to a second year of college.

\section{Race and ethnicity}

National data show approximately one-third of all community college students are non-White (Cohen \& Brawer, 2008), a number which is supported by the current study (37\% non-White students). The majority of prior research (Attewell et al., 2006; Bailey et al., 2010; USDoE, 2006) has found non-White students persist to graduation at lower rates than do White students. The lower graduation rates are particularly true for Black 
students. There is some uncertainty in lower persistence rates for non-White students as prior research has identified no difference (Fike \& Fike, 2008) between racial and ethnic groups, or that Black and Hispanic students persist at higher rates (Hawley \& Harris, 2005).

The current study has found that race and ethnicity is a significant and strong predictor of persistence. Specifically, Black students persist at significantly lower rates and other non-White racial and ethnic groups persist at significantly higher rates. A Black student is $42.6 \%$ less likely to persist as is a non-Black student and other nonWhite ethnicities are $29 \%$ more likely to persist than members of other ethnicities.

Separating Black racial and ethnic students from students in other races and ethnicities creates a situation where the findings of the current study do not agree with previous research. Namely, previous research has found non-White students have lower persistence, and the current study has found students of non-White ethnicities who are not Black persist at higher rates. The current study has found the relative effect size of being Black was much lower than the effect size of being of a different racial and ethnic, nonmajority group. The definition of groups may be the reason for contradictory findings in past research. If being Black provides an opposite effect on persistence as being from a different racial and ethnic group, results from previous research would differ for different combinations of racial and ethnic group of non-White depending on the relative size of the Black and non-Black groups in the combined group.

\section{Researcher insights}

The persistence of students is a difficult subject to study, as students not only 
enroll in higher education for many different reasons, but there are many different reasons for which students chose to end their enrollment in higher education (Cohen \& Brawer, 2008). This is a particularly difficult as the non-persistence of students may not even be viewed as a problem by the student (Bailey et al., 2010; Cohen \& Brawer, 2008) and may be due to attributes which are not academically related (Attewell et al., 2011). Many researchers assert that differences in the persistence of students are related more to factors present in the student prior to them reaching higher education institutes (Alliance for Excellent Education, 2011; Cohen \& Brawer, 2008; Jenkins \& Boswell, 2002), particularly education deficiencies from high school (Wilson, 2008). The current study found that developmental status and gender were both weak predictors of persistence whereas age and race and ethnicity were strong predictors. These results lend support to the assertions of prior researchers who have reported factors which are present prior to the higher education experience of a student carry more weight in the persistence of students (Attewell et al., 2006).

An additional reason for differences in persistence rates from students from different racial and ethnic groups may have very different responsibilities and expectations outside the higher educational institution than students from other racial and ethnic groups. Student responsibilities and family expectations from factors other than education have been shown to affect persistence (Braxton et al., 2005).

In examining the effect age has on the persistence of students, the expectations and experiences of non-traditionally aged students are often quite different than traditionally aged college students, particularly deriving from non-academic factors. 
Non-traditionally aged students will generally have more family, work, and life responsibilities than traditionally aged students. The goals for higher education are often different for students in different age categories. Particularly, many traditionally aged students are attending community colleges for associate degrees and transfer to four-year universities and many non-traditionally aged students are attending to improve work skills and to enroll in continuing education courses. Thus, often a non-traditionally aged student has a greater, more immediate motivation to be successful and complete their study quickly than does a traditionally aged student and motivation positively affects persistence (Jefferson, 2010). These factors may cause the significant difference in persistence which was found in the current study based on the age of the student.

The differences in persistence rates had relatively low effect sizes for students of different genders and different developmental statuses. One possible reason these two factors have a lower effect on persistence is they are less affected by factors outside the control of the institution than are age and racial and ethnic status.

Even though the current study did find significant differences between the persistence rates of different groups of students, the overall predictability of the model is extremely low. The model which includes the variables developmental status, age, race and ethnicity, and gender of the students only improves the ability to predict persistence by $0.1 \%$ and accounts for less than $2 \%$ of the total variation in the fall-to-fall persistence rates. Therefore, the persistence of students cannot be well explained by the factors included in the current study.

\section{Implications and recommendations for practitioners}


Persistence is difficult to attribute to any one cause, particularly as the persistence of a particular student usually is determined by the student. Practitioners in community colleges should understand the phenomenon of persistence is largely out of their control.

Despite the difficultly for higher education institutions to affect persistence, this study has identified non-traditionally aged students and Black students as having significantly lowest persistence than other groups. Therefore, community colleges should consider addressing these two groups of students to positively influence their decision to persist. Several possible ways to do this are to assign an advisor to non-traditionally aged students at time of enrollment, to create student interest groups of particular interest to Black and non-traditionally aged students, and to create learning communities directed towards students in these two groups to increase opportunities to interact with students of similar backgrounds and educational goals.

Previous studies have linked the persistence of students to factors not related to the higher education institute. These factors include the motivation, finances, integration in the institute, and family responsibilities of the student. Personal contact with the student by a member of the college can provide the student a guide to available resources which the college offers its students. This personal contact can help not only with integrating the student into the institution but also with aiding the student with addressing and overcoming other issues. Community colleges should consider assigning an advisor to every incoming student and requiring each student to meet with an advisor prior to registering for classes.

Finally, the non-persistence of a student may not even be a problem. For 
example, a student enrolled full-time in a four-year university who elected to take one course at a community college during the summer would be listed in the current study as non-persisting even though that student achieved their goal in the community college. Community colleges should consider recording the incoming goals of each new student to better determine the persistence of that student towards their goal. Furthermore, this determination of goals could be performed at the beginning of each subsequent semester as part of the enrollment process. This could aid community colleges in determining a more accurate persistence rate as students in community colleges have many different goals and desired outcomes.

\section{Suggestions for Future Research}

Even though the current study found there is a significant difference in the success of developmental and non-developmental students, the effect size for this difference is low. However, the current study also found that $60 \%$ of developmental students never attempt a college-level mathematics course. Further research should be conducted to determine the reasons for which developmental students do not attempt a college-level course. This will help determine if there are factors which can be addressed by higher education institutions which would improve the percentage of developmental students reaching college-level mathematics courses.

The current study found that developmental students persist at lower rates than non-developmental students. This result is contrary to most of the past literature. An ex post facto research design is not able to address the reasons for the persistence or nonpersistence of students. Further research should be conducted to identify characteristics 
of persisting and non-persisting students. This would determine if there are differences between students who persist and those who do not. Additionally, analysis of the group of students who did not enroll in a mathematics course their first semester should be conducted to see if there are any differences between that group and students who do take a mathematics course their first semester.

Persistence of students in the literature has been attributed to many different reasons; most of these reasons are factors which are out of the control of the institution. Gathering demographic and institutional data cannot address factors such as personal finances, family obligations, and other personal factors. Further research should be conducted to determine if there are personal factors which may be able to be addressed by the institution to improve the over-all persistence of students.

\section{Summary}

The purpose for this study was to examine the differences in the success and persistence of developmental students when compared to non-developmental students. Previous research has generally reported developmental students have similar levels of success and greater levels of persistence than non-developmental students, with some support for other results. The current study found that developmental students who enroll in a college-level mathematics course succeed at lower rates than non-developmental students. Among students who took a mathematics course in their first semester of school, developmental students persist at lower rates than non-developmental students do. However, the adjusted odds ratios of developmental status on both success and persistence of students is not large signifying the differences are not large. 
Age moderates the effect of developmental status on both success and persistence. Developmental education helps traditionally aged students reach levels of success closer to that of non-developmental students more than it does for non-traditionally aged students. Non-traditionally aged developmental students persist at higher rates than do traditionally age developmental students.

Whereas the effects of developmental status on the success and persistence of Virginia community college students is low, the effects of gender, race and ethnicity, and age are much higher regardless of developmental status. Non-traditionally aged students succeed at significantly higher rates than traditionally aged students, and Black students succeed at significantly lower rates than non-Black students. Traditionally aged students persist at significantly higher rates than non-traditionally aged students and Black students persist at significantly lower rates than non-Black students. 


\section{REFERENCES}

Achieving the Dream (2011). Data notes: Keeping informed about achieving the dream data, 6(1). Retrieved from http://www.achievingthedream.org/sites/default/files/news/DataNotes_JanFeb_20 10.pdf

Akst, G. (2007). Post secondary attendance and success patterns: An interview with Clifford Adelman. Journal of Developmental Education, 31(2), 14-16.

Alcorta, L. S. (2009). Student achievement in developmental mathematics and effective practices in developmental education: A study of an urban community college district in Texas. (Doctoral dissertation). Retrieved from Proquest Information and Learning Company. (UMI number 3389892)

Alliance for Excellent Education. (2011, May). Saving now and saving later: How high school reform can reduce the nation's wasted remediation dollars. (Issue Brief). Washington, D. C. Retrieved from http://www.all4ed.org/files/SavingNowSavingLaterRemediation.pdf

Alvarez, A. L. (2008). Academic performance: A correlational study between a remedial writing course and college English I grades. (Doctoral dissertation). Retrieved from Proquest Information and Learning Company. (UMI number 3326213)

Arbona, C., \& Nora, A. (2007). The influence of academic and environmental factors on Hispanic college degree attainment. The Review of Higher Education, 30(3), 247269. 
Attewell, P., Heil, S., \& Reisel, L. (2011). Competing explanation of undergraduate noncompletion. American Educational Research Journal, 48(3), 536-559. Doi: $10.3102 / 0002831210392018$

Attewell, P., Lavin, D., Domina, T., \& Levey, T. (2006). New evidence on college remediation. The Journal of Higher Education, 77(5), 886-924.

Ayers, D. F. (2002). Mission priorities of community colleges in the southern United States. Community College Review, 30(3), 11-30. doi:

$10.1177 / 009155210203000302$.

Bahr, P. R. (2007). Double jeopardy: Testing the effects of multiple basic skill deficiencies on successful remediation. Research in Higher Education, 48(6), 695-725. doi: 10.1007/s11162-006-9047-y

Bahr, P. R. (2008). Does mathematics remediation work? A comparative analysis of academic attainment among community college students. Research in Higher Education, 49, 420-450.

Bailer, D. L. (2006). A multivariate analysis of the relationship between age, selfregulated learning, and academic performance among community college developmental students. (Doctoral dissertation). Retrieved from Proquest Information and Learning Company. (UMI number 3201703)

Bailey, T., Calcagno, J. C., Jenkins, D., Kienzl, G., \& Leinbach, T. (2005). The effects of institutional factors on the success of community college students. Community College Research Center Brief \#24. New York. Columbia University. (ERIC Document Reproduction No. ED484345) 
Bailey, T., Jeong, D. W., \& Cho, S. W. (2010). Referral, enrollment, and completion in developmental education sequences in community colleges. Economics of Education Review, 29, 255-270.

Bailey, T. (2009). Challenge and opportunity: Rethinking the role and function of developmental education in community college. New Directions for Community Colleges, 145, 11-30. DOI: $10.1002 / \mathrm{cc} .352$

Bauer, D. A. (2010). Do they work? Developmental courses in mathematics and English at Sitting Bull College. (Doctoral dissertation). Retrieved from Proquest Information and Learning Company. (UMI number 3448933)

Bettinger, E. P., \& Long, B. T. (2005). Remediation at the community college: Student participation and outcomes. New Directions for Community Colleges, 129, 17-26.

Bettinger, E. P., \& Long, B. T. (2009). Addressing the needs of underprepared students in higher education: Does remediation really work? The Journal of Human Resources, 44(3), 736-771.

Bharath, D. (2009). Effects of student-teacher interactions on persistence of underprepared community college students. (Doctoral dissertation). Retrieved from Proquest Information and Learning Company. (UMI number 3377918)

Biegel, P. J. (2009). Is remediation the successful path? A study of a community college preparatory program. (Doctoral dissertation). Retrieved from Proquest Information and Learning Company. (UMI number 3372234)

Boylan, H. R., Bonham, B. S. (2007). 30 years of developmental education: A retrospective. Journal of Developmental Education, 30(3), 2-4. 
Boylan, H. R., Bonham, B. S., \& Tafari, G. N. (2005). Evaluating the outcomes of developmental education. New Directions for Institutional Research, 125, 59-72.

Braxton, J. M., Hirschy, A. S., \& McClendon, S. A. (2004). Understanding and reducing college student departure: ASHE-ERIC higher education report, volume 30 , number 3. Retrieved from http://www.josseybass.com/WileyCDA/WileyTitle/productCd0787972827,descCd-tableOfContents.html

Buchmann, C., \& DiPrete, T. A. (2006). The growing female advantage in college completion: The role of family background and academic achievement. American Sociological Review, 71(4), 515-541.

Byrd, M. L. (2004). Developmental education at a southeast Mississippi community college. (Doctoral dissertation). Retrieved from Proquest Information and Learning Company. (UMI number 3165217)

Byrd, K. L. \& Macdonald, G. (2005). Defining college readiness from the inside out: First-generation college student perspectives. Community College Review, 33(1), 22-37.

Calcagno, J. C. (2007). Evaluation the impact of developmental education in community colleges: A quasi-experimental regression-discontinuity design. (Doctoral dissertation, Columbia University 2007). Retrieved from Proquest Information and Learning Company. UMI number 3266545. 
Calcagno, J. C., Bailey, T., Jenkins, D., Kienzl, G., \& Leinbach, T. (2008). Community college student success: What institutional characteristics make a difference? Economics of Education Review, 27, 632-645. doi:

10.1016/j.econedurev.2007.07.003

Calcagno, J. C., Crosta, P., Bailey, T., \& Jenkins, D. (2007a). Stepping stones to a degree: The impact of enrollment pathways and milestones on community college student outcomes. Research in Higher Education, 48(7), 775-801.

Calcagno, J. C., Crosta, P., Bailey, T., \& Jenkins, D. (2007b). Does age of entrance affect community college completion probabilities? Evidence from a discretetime hazard model. Educational Evaluation and Policy Analysis, 29(3), 218-235.

California Community Colleges. Chancellor's office. (2011a). Program retention/success rates. Retrieved October 27, 2011 from https://misweb.cccco.edu/mis/onlinestat/ret_sucs.cfm

California Community Colleges. Chancellor's office. (2011b). Student demographics by academic year. Retrieved October 27, 2011 from https://misweb.cccco.edu/mis/onlinestat/studdemo_annual_college.cfm

Capps, R. (2010). A grounded theory of adult student persistence. (Doctoral dissertation). Retrieved from Proquest Information and Learning Company. (UMI number 3412552)

Casazza, M. E. (1999). Who are we and where did we come from? Journal of Developmental Education, 23(1). 
Cho, S. W. (2011). Essays on developmental student success and program impacts in community colleges. (Doctoral dissertation). Retrieved from Proquest Information and Learning Company. (UMI number 3451693)

Cohen, A. M., \& Brawer, F. B. (2008). The American Community College $\left(5^{\text {th }}\right.$ ed.). San Francisco: Jossey-Bass.

Cooper, D. L. (2009). Demographic and academic characteristics of developmental education students at a midwestern community college. (Doctoral dissertation). Retrieved from Proquest Information and Learning Company. (UMI number 3374218)

Corey Legge, K. P. (2010). Does mandatory supplemental instruction work in developmental math education? A study of students enrolled in developmental math courses at a suburban community college in the northeast. (Doctoral dissertation, Temple University 2010). Retrieved from Proquest Information and Learning Company. (UMI number 3408705)

Crews, D. M., \& Aragon, S. R. (2004). Influence of a community college developmental education writing course on academic performance. Community College Review, $32(2), 1-18$.

Dahlstrom, E. R. (2005). African American students underachieve in basic math and English classes when compared to Caucasian students: An action plan. (Doctoral dissertation). Retrieved from Proquest Information and Learning Company. (UMI number 3180316) 
Dotzler, J. J. (2003). A note on the nature and history of post-secondary developmental education in America. Mathematics and Computer Education, p. 121-125.

DuBray, D. T. (2005). A developmental climb: Student retention within mathematics courses among urban community college students. (Doctoral dissertation, The University of Southern California 2005). Retrieved from Proquest Information and Learning Company. UMI number 3196801.

Duranczyk, I. M., \& Higbee, J. L. (2006). Developmental mathematics in 4-year institutions: Denying access. Journal of Developmental Education, 30(1), 22-31.

Escobedo, G. (2007). A retention/persistence intervention model: Improving success across cultures. Journal of Developmental Education, 31(1), 12-14, 16-17, 37.

Fast Facts, Virginia Community College System (n.d.). Retrieved February 2, 2011 from http://www.vccs.edu/WhoWeAre/FastFacts/tabid/79/Default.aspx

Fike, D. S. \& Fike, R. (2007). Does faculty employment status impact developmental math outcomes? Journal of Developmental Education, 31(1), 2-11.

Fike, D. S., \& Fike R. (2008). Predictors of first-year student retention in the community college. Community College Review, 36(2), 68-88.

Florida Department of Education. (2011a). College readiness among first time in college (FTIC) students. Retrieved October 27, 2011 from http://www.fldoe.org/cc/OSAS/Evaluations/pdf/Zoom2011-04.pdf

Florida Department of Education. (2011b). The fact book: Report for the Florida college system. Retrieved October 27, 2011 from http://www.fldoe.org/cc/OSAS/Evaluations/pdf/Zoom2011-04.pdf 
Germanna Community College (2002, January). Students' outcomes in developmental education, 1994-95 through 1999-2000. (ERIC Document Reproduction No. ED459900)

Goldstein, M. T. \& Perin, D. (2008). Predicting performance in a community college content-area course from academic skill level. Community College Review, 36(2), 89-115.

Gonzales, S. R. (2007). Remedial education and its relationship to academic performance and retention of students at Central Arizona College: A case study. (Doctoral dissertation). Retrieved from Proquest Information and Learning Company. (UMI number 3271360)

Gonzalez, J. (2011, July 31). Va. Community colleges dive headfirst into remedial-math redesign. The Chronicle of Higher Education, 2011, July 31

Graybeal, S. E. (2007). A study of first-time full-time freshman's attributes and their associations with fall-to-fall retention rates at a two-year public community college. (Doctoral dissertation). Retrieved from Proquest Information and Learning Company. (UMI number 3256789)

Grubb, W. N., \& Associates. (1999). Honored but invisible: An inside look at teaching in community colleges. New York: Routledge.

Hawley, T. H., \& Harris, T. A. (2005). Student characteristics related to persistence for first-year community college students. Journal of College Student Retention, 7(12), 117-142. 
Higbee, J. L., Arendale, D. R., \& Lundell, D. B. (2005). Using theory and research to improve access and retention in developmental education. New Directions for Community Colleges, 129, 5-15.

Higher ed groups to examine college completion. (2011, October 17). Community College Times. Retrieved from http://www.communitycollegetimes.com/Pages/Campus-Issues/Higher-edgroups-to-examine-college-completion.aspx

Illich, P. A., Hagan, C., \& McCallister, L. (2004). Performance in college-level courses among students concurrently enrolled in remedial courses: policy implications. Community College Journal of Research and Practice, 28, 435-453. doi: $10.1080 / 10668920490444463$

James, A. N. (2007). Gender differences and the teaching of mathematics. Inquiry, 12(1), 14-25. Retrieved October 8, 2009 from http://www.vccaedu.org/inquiry/inquiryspring-2007/i-12-James.html

Jefferson, D. (2010). Persistence of the academically underprepared student at a 2-year college: A phenomenological exploration using Tinto's integrative model. (Doctoral dissertation). Retrieved from Proquest Information and Learning Company. (UMI number 3438128)

Jenkins, A., \& Boswell, K. (2002). State policies on community college remedial education: Findings from a national survey. Denver, CO: Education Commission of the States, Center for Community College Policy. Retrieved September 21, 2011 from http://www.ecs.org/clearinghouse/40/81/4081.pdf 
Johnson, M., \& Kuennen, E (2004). Delaying developmental mathematics: The characteristics and the costs. Journal of Developmental Education, 28(2), 24-29.

Karp, M. M., Hughes, K. L., \& O'Gara, L. (2010). An exploration of Tinto's integration framework for community college students. Journal of College Student Retention, 12(1), 69-86.

Kendall, J. S., Pollack, C.., Schwols, A., \& Snyder, C. (2007). High school standards and expectations for college and the workplace. Issues and answers. REL 2007 - No. 001. Regional Educational Laboratory Central. Denver, CO. (ERIC Document Reproduction Service No. ED497793).

Kisker, C. B., \& Outcalt, C. L. (2005). Community college honors and developmental faculty: Characteristics, practices, and implications for access and educational equity. Community College Review, 32(2), 1-21.

Kolajo, E. F. (2004). From developmental education to graduation: A community college experience. Community College Journal of Research and Practice, 28, $365-371$.

Kozeracki, C. A. (2002). ERIC review: Issues in developmental education. Community College Review, 29(4), 83-100.

Kozeracki, C. A., \& Brooks, J. B. (2006, Winter). Emerging institutional support for developmental education. New Directions for Community Colleges, 136, 63-73. DOI: $10 . \mathrm{i} 002 / \mathrm{cc} .260$ 
Lesik, S. A. (2007). Do developmental mathematics programs have a causal impact on student retention? An application of discrete-time survival and regressiondiscontinuity analysis. Research in Higher Education, 48(5), 583-608. doi: $10.1007 / \mathrm{s} 11162-006-9036-1$

Levin, H. M. \& Calcagno, J. C. (2008). Remediation in the community college: An evaluator's perspective. Community College Review, 35(3), 181-207.

Linfante, F. A. (2002). Students' success in college-level English composition after completing developmental English in an urban community college.. (Doctoral dissertation). Retrieved from Proquest Information and Learning Company. (UMI number 3039315)

Lynch-Newberg, S. A. (2010). The retention, success, and progress rates of rural females in traditional lecture and online developmental mathematics courses. (Doctoral dissertation). Retrieved from Proquest Information and Learning Company. (UMI number 3452860)

Martinez, T.P., \& Martinez, A.P. (2006). Texas tackles remediation reform. The Hispanic Outlook in Higher Education, 16(22), 11-13.

Martino, G. \& Wilson, W. S. (2009). Doing the math: Are Maryland's high school math standards adding up to college success? Retrieved from The Abell Foundation website: http://www.abell.org/pubsitems/ed_DoingMath_0409.pdf 
Martorell, P., \& McFarlin, I. (2007). Help or hindrance? The effects of college remediation on academic and labor market outcomes. Paper presented at the Center for Policy Research Seminar Series, Syracuse University, Syracuse, N.Y. Retrieved from http://www.maxwell.syr.edu/uploadedFiles/cpr/events/cpr_seminar_series/previo us_seminars/mcfarlin.pdf

McIntosh, M. F., \& Rouse, C. E. (2009, February). The other college: Retention and completion rates among 2-year college students. Retrieved from Center for American Progress website: http://www.americanprogress.org/issues/2009/02/pdf/two_year_colleges.pdf

Meyers, L. S., Gamst, G., \& Guarino, A. J. (2006). Applied multivariate research: Design and interpretation. Thousand Oaks, CA: Sage Publications.

Miglietti, C. L., \& Strange, C. C. (1998). Learning styles, classroom environment preferences, teaching styles, and remedial course outcomes for underprepared adults at a two-year college. Community College Review, 26(1), 1-19.

Mireles, S. V. (2010). Theory to practice. Developmental mathematics program: A model for change. Journal of College Reading and Learning, 40(2), 81-90.

Moore, Z. S. (2006). Student persistence in higher education: A community college perspective. (Doctoral dissertation, The University of Missouri - Columbia 2006). Retrieved from Proquest Information and Learning Company. UMI number 3242083. 
Moss, B. G., \& Yeaton, W. H. (2006). Shaping policies related to developmental education: An evaluation using the regression-discontinuity design. Educational Evaluation and Policy Analysis, 28(3), 215-229.

National Association for Developmental Education (n.d.). About Developmental Education. Retrieved October 3, 2011 from: http://www.nade.net/AboutDevEd.html\#Definition

Oklahoma State Regents for Higher Education (2008). Annual Student Remediation Report. Retrieved from http://www.okhighered.org/studiesreports/remediation/remediation-report-3-08.pdf

Oudenhoven, B. (2002). Remediation at the community college: Pressing issues, uncertain solutions. New Directions for Community Colleges, 117, 35-44.

Pampel, F. C. (2000). Logistic regression: A primer. Sage University Papers Series on Quantitative Applications in the Social Sciences, 07-132. Thousand Oaks, CA: Sage.

Parmer, P., \& Cutler, J. (2007). Easing the transition: Building better bridges between developmental and college-level math. Journal of Applied Research in the Community College, 15(1), 37-45.

Parsad, B., Lewis, L., \& Greene, B. (2003). Remedial education at higher education institutions in fall 2000. Retrieved from National Center for Educational Statistics: http://nces.ed.gov/pubs2004/2004010.pdf 
Pelkey, D. (2011). Factors supporting persistence of academically underprepared community college students. (Doctoral dissertation). Retrieved from Proquest Information and Learning Company. (UMI number 3464393)

Provasnik, S., \& Planty, M. (2008). Community colleges: Special supplement to the condition of education 2008 (NCES 2008-033). National Center for Education Statistics, Institute of Education Sciences, U.S. Department of Education. Washington, DC.

Roksa, J., Jenkins, D., Jaggars, S. S., Zeidenberg, M., \& Cho, S. W. (2009). Strategies for promoting gatekeeper course success among students needing remediation: Research report for the Virginia Community College System. Community College Research Center. New York. Columbia University. (ERIC Document Reproduction No. ED507392)

Saxon, D. P., \& Boylan, H. R. (2001). The cost of remedial education in higher education. Journal of Developmental Education, 25(2), 2-8.

Shelton, A. R., \& Brown, R. S. (2008, March). Measuring the alignment of high school and community college math assessments. Paper presented at the Annual Meeting of the American Educational Research Association, New York City.

Silverman, L. H. (2010). Academic progress in developmental math courses: A comparative study of student retention. (Doctoral dissertation). Retrieved from Proquest Information and Learning Company. (UMI number 3412943)

Southard, A. H., \& Clay, J. K. (2004). Measuring the effectiveness of developmental writing courses. Community College Review, 32(2), 39-50. 
Spann, M. G., Jr. (2000). Remediation: A must for the $21^{\text {st }}$ century society. (Report No. CC 004). Washington DC: Department of Education; Amoco Foundation, Inc., Chicago. (ERIC Document Reproduction No. ED439771)

Stewart, S. F. (2010). An examination of pre-entry and academic performance factors that predict persistence of academically underprepared students at a public research university. (Doctoral dissertation). Retrieved from Proquest Information and Learning Company. (UMI number 3403011)

Sullivan, K. H. (2010). Using student characteristics in an institutional context to examine predictors of a community college student passing a developmental education course: A multilevel analysis. (Doctoral dissertation). Retrieved from Proquest Information and Learning Company. (UMI number 3442562)

Taylor, M. K. (2009). The effects of academic and social integration on two-year college students' persistence in developmental courses. (Doctoral dissertation). Retrieved from Proquest Information and Learning Company. (UMI number 3369289)

Threadgill, P. S. (2005). Adult academic performance and persistence: A comparison of developmental and non-developmental students. (Doctoral dissertation). Retrieved from Proquest Information and Learning Company. (UMI number 3203171)

Tinto, V. (1993). Leaving college: Rethinking the causes and cures of student attrition (2nd ed.). Chicago: University of Chicago Press.

Tinto, V. (1997). Classrooms as communities: Exploring the educational character of student persistence. The Journal of Higher Education, 68, 599-623. 
U.S. Department of Education. (2000). Corporate involvement in education: Achieving our national education priorities. The seven priorities of the U.S. Department of Education. Washington, DC: (ERIC Document Reproduction Service No. ED440307)

U.S. Department of Education. (2006). A test of leadership: Charting the future of U.S. higher education: A report of the commission appointed by Secretary of Education Margaret Spellings. Retrieved from http://www2.ed.gov/about/bdscomm/list/hiedfuture/reports/final-report.pdf Virginia Community College System (n.d.). Policy Manual. Retrieved March 7, 2011 from http://www.vccs.edu/WhoWeAre/PolicyManual/tabid/103/Default.aspx Virginia Community College System, Office of Institutional Research \& Effectivness. (2009). The turning point: Developmental education in Virginia's Community Colleges. Retrieved from http://www.vccs.edu/Portals/0/ContentAreas/AcademicServices/The_Turning_Poi nt_DETF_Report_200909.pdf

Virginia Community College System, Office of Institutional Research \& Effectivness. (2011). Developmental education annual report: Tracking the fall 2006 cohort and five-year historical trends. Retrieved from http://www.vccs.edu/Portals/0/ContentAreas/AcademicServices/Dev_Ed_Annual Report_201102.pdf 
Virginia Department of Education. (2011). The standards \& SOL-based instructional based resources: Mathematics. Retrieved from http://www.doe.virginia.gov/testing/sol/standards_docs/mathematics/index.shtml Waycaster, P. (2001). Factors impacting success in community college developmental mathematics courses and subsequent courses. Community College Journal of Research and Practice, 25(5/6), 403-416.

Wilson, W. S. (2008). Are our students better now? Department of Mathematics, Johns Hopkins University, Baltimore, MD. Retrieved April 11, 2009, from, http://media.hoover.org/documents/ednext_20084_88_unabridged.pdf

Yates, K. J. (2010). Graduation Rates: A comparison of first-time, full-time freshmen who entered a community college prepared and those who entered underprepared for college-level work. (Doctoral dissertation, East Tennessee State University 2010). Retrieved from Proquest Information and Learning Company. (UMI number 3410189)

Zhu, Q., \& Polianskaia, G. (2007). A comparison of traditional lecture and computermediated instruction in developmental mathematics. Research and Teaching in Developmental Education, 24(1), 63-82 


\section{APPENDIX A}

\section{PROBABILITY OF SUCCESS IN THE FIRST COLLEGE-LEVEL MATHEMATICS COURSE}

\begin{tabular}{|c|c|c|c|c|}
\hline & & & Developmental & Non-Developmental \\
\hline \multirow[t]{6}{*}{ Traditionally aged } & Female & White & $65 \%$ & $67 \%$ \\
\hline & & Black & $54 \%$ & $55 \%$ \\
\hline & & Other & $63 \%$ & $67 \%$ \\
\hline & Male & White & $55 \%$ & $58 \%$ \\
\hline & & Black & $43 \%$ & $46 \%$ \\
\hline & & Other & $53 \%$ & $58 \%$ \\
\hline \multirow[t]{6}{*}{ Non-traditionally aged } & Female & White & $77 \%$ & $84 \%$ \\
\hline & & Black & $68 \%$ & $76 \%$ \\
\hline & & Other & $76 \%$ & $84 \%$ \\
\hline & Male & White & $69 \%$ & $78 \%$ \\
\hline & & Black & $58 \%$ & $69 \%$ \\
\hline & & Other & $67 \%$ & $79 \%$ \\
\hline
\end{tabular}




\section{APPENDIX B}

\section{PROBABILITY OF PERSISTENCE TO A SECOND YEAR OF COLLEGE}

Developmental Non-Developmental

$\begin{array}{lllll}\text { Traditionally aged } & \text { Female } & \text { White } & 60 \% & 66 \% \\ & & \text { Black } & 53 \% & 56 \% \\ & \text { Male } & \text { White } & 57 \% & 71 \% \\ & & \text { Black } & 51 \% & 62 \% \\ \text { Non-traditionally aged } & \text { Female } & \text { White } & 54 \% & 52 \% \\ & & \text { Black } & 48 \% & 68 \% \\ & & \text { Other } & 60 \% & 53 \% \\ & & \text { White } & 51 \% & 42 \% \\ & & \text { Black } & 45 \% & 59 \% \\ & & \text { Other } & 58 \% & 49 \%\end{array}$




\title{
VITA
}

\section{James Dael Wolfle}

Assistant Professor

J. Sargeant Reynolds Community College, Richmond, VA 23285 (804) $523-5530$ JWolfle@reynolds.edu

\section{Education}

Ph.D. Curriculum and Instruction, Old Dominion University, 2012

M.Ed. Adult Education, Penn State University, 2006

B.S. Mathematics, Penn State University, 1991

\author{
Professional Experience \\ 2010 - present \\ Assistant Professor, J. Sargeant Reynolds Community College, \\ Mathematics, Richmond, VA. \\ $2006-2010$ \\ Assistant Professor, Tidewater Community College, \\ Mathematics, Chesapeake, VA. \\ $2002-2006$ \\ Head Age Group Coach, TIDE Swim Team, Virginia Beach, VA. \\ $1998-2002$ \\ Adjunct Instructor, James Madison University, Kinesiology, \\ Harrisonburg, VA. \\ $1999-2002$ \\ Head Coach, Harrisonburg City Schools, Harrisonburg High \\ $1996-2002$ \\ School, Swimming, Harrisonburg, VA \\ $1995-1996$ \\ Head Coach, Valley Area Swim Team, \\ Harrisonburg, VA. \\ Head Age Group Coach, Valley Area Swim Team, Harrisonburg, \\ VA. \\ $1991-1995$ \\ Head Coach, Blacksburg Sunfish Swim Team, Blacksburg, VA
}

\section{Publications}

In press The Success and Persistence of Developmental Mathematics Students Based on Age and Ethnicity in a Virginia Community College

\section{Presentations}

2011 Professional Development Day, J. Sargeant Reynolds Community College, Richmond, VA.; Faculty Grant Developmental Round Table, Nancy Mihalko, Chuck Swaim, James Wolfle, Tahir Aziz, Cynthia De Riemer 